\title{
Augmentation of information in educational objects: Effectiveness of arrows and pictures as information for actions in instructional objects
}

\author{
Andre A. Pekerti \\ The University of Queensland, Australia
}

\begin{abstract}
The use of information and communication technology (ICT) in education is now central to facilitating links between learners, resources and instructors. Regardless of whether it is used in distance education or educational objects, ICT enables educators to package education opportunities in an increasing number of alternative ways so as best to meet the varying needs of the end user. Currently, one of the challenges that face instructors is to develop materials that enhance the learner-content interaction by reducing extraneous cognitive load while at the same time facilitating learning. This study explored the effectiveness of pictorial information and augmentation in instructions and educational objects. Dual coding theory is used to suggest that information that can be processed via separate but interconnected systems will facilitate faster processing and deeper learning of the information. University students were randomly assigned to six experimental conditions to perform a novel task using six different instruction manuals. A 3 (text, text-pictorial, text-pictorial-arrows) X 2 (picture of object vs. no picture of object) design was used to test whether augmenting text with pictorial information provided additional valuable information in instructional settings. Results partially support this multimedia effect; participants exhibited superior performance in a Text-Pictorial and Text-Pictorial-Arrows format over Text format. A picture of the object also facilitated superior performance on both the assembly and operating tasks, especially in a text format. Overall, combinations of text-pictorial and text-pictorial-arrows facilitated faster assembly and operation; they reduced errors, extra procedures, and unsuccessful assemblies (uncorrected errors). Results also support the idea that arrows convey unique types of information and function. In particular, arrows may attune people to important information and/or convey information movement that guides actions during tasks. Practical implications are discussed in relation to the type of information combinations that may lead to superior instructional design of instructional objects and research, including how to reduce errors of omission.
\end{abstract}

\section{Introduction}

The use of information and communication technology (ICT) in education is now central to facilitating links between learners, resources, and instructors. Regardless of whether it is used in distance education (DE) or for the widely used educational objects, ICT enables educators to package education opportunities in an increasing number of alternative ways so as best to meet the varying needs of different learners (Khoshemehr \& Nazemi, 2013; Simonson, Schlosser, \& Orellana, 2011).

A recent review of research on DE suggests that in the 21 st century DE is going through its third phase of the dominant medium used to deliver content, moving from correspondence study, to the use of mass media and now the use of ICT to connect learners, resources and instructors (Simonson et al., 2011). As a tool that is used to communicate, create, disseminate, store, and manage information in a learning context (Lawal \& Oloyede, 2013; Malapile \& Keengwe, 2013) ICT has its own advantages and disadvantages. For example, as with mass media ICT can deliver educational objects to a large number of learners at the same time. However, it can also place large cognitive demands on users during learning situations. Notwithstanding the advantages and disadvantages associated with ICT and its use in DE, Simonson et al. (2011) were astute in pointing out that the focus of DE has also changed in the 21 st century with learnercentred approaches being the main agenda. They further acknowledged that we must go beyond the flaws associated with the use of technology and focus on the business of educating, stating "Technology is not the issue. How and what we want learners to learn is the issue and technology is a tool" (Simonson et al., 2011; p. 132).

There seems to be a consensus among DE practitioners that using ICT changes teaching methodology. In the past, instructors dominated a large part of the courses they delivered; now learners play a more active role either through self-learning methods or centralized learning. Khoshemehr and Nazemi (2013) further point out that when used in adult learning or post-school situations the role of the instructor has also 
changed when modern technology and/or ICT is used, whereby the roles of the instructor now includes creating the knowledge delivery environment as well the knowledge itself.

Moore (1989) and more recent authors indicate that there are three crucial types of interactions in educational situations: (a) instructor-learner, (b) learner-learner, and (c) learner-content interactions (Abrami, Bernard, Bures, Borokhovski, \& Tamim, 2011; Bol \& Garner, 2011; Kanuka, 2011). Scholars acknowledge that one of the central issues associated with DE is the fact that learners have to make their own decisions about learning since there is limited dialogue with the instructor (Kanuka, 2011 - high level of transactional distance). Additionally when ICT is used compared to the use of permanent forms of presentation such as written text the information can be transient. For example, in DE when written text are transformed into spoken words or when static educational objects are transformed into animation using ICT, the information becomes ephemeral to the listener and observer respectively (Kalyuga, 2012), in the sense that one cannot simply scan or browse through the information to check on facts or gaps in information. One has to go back and rewind the audio and/or visual animation to access the information again. Scholars argue that in this situation the use of ICT may actually present extraneous cognitive load on learners when learners are interacting with the content of their courses or educational objects (Abrami et al., 2011; Kalyuga, 2012; Rouet, 2009). In other words, to proceed with gaps in information or the act of rewinding the audio and/or visual animation is an extra cognitive load to the learners.

In the context of ICT, Khoshemehr and Nazemi (2013) argue that education objects are any type of knowledge set that is used in support of an educational objective, as such, they can come in any form and can take advantage of ICT as a tool for delivery (Alexander \& Hammond, 2012; Abrami et al., 2011; Lawal \& Oloyede, 2013; Simonson et al., 2011). The current challenge that faces educational object designers and instructors is, therefore, developing materials that enhance the learner-content interaction and at the same time reduce extraneous cognitive load to facilitate learning. This paper argues that this is a challenge not only for educators in DE, but also challenges those that design instructional objects, which is any type of knowledge set that is disseminated to the public for the purpose of instructing the end-user via ICT.

Kalyuga (2012; p. 191) implied that in interactive DE the use of modern ICT may involve "multiple representations, networks of interlinked information sources, and high levels of learner control." This however, can lead to extraneous load that in turn impedes learning; for example, it can be difficult for learners to maintain learning goals while simultaneously searching or looking for information within the educational and instructional objects. One of the solutions to improve DE is to reduce extraneous cognitive load for learners by using visual cues such as arrows or highlights to provide attention-directing cues (Abrami et al., 2011; Kalyuga, 2009; 2012; Mayer, 2008). This recommendation fits with Rouet's (2009) conclusion that for learners to successfully interact with content material they must know how to locate it efficiently; including the idea that in DE sequencing relevant information is crucial to the learning process and managing cognitive load (Kalyuga, 2012; Khoshemehr \& Nazemi, 2013).

Mayer's work (e.g., 2005a; 2005b; 2008) has documented that visual information can function to reduce extraneous cognitive load during learning contexts. Research suggests that one fundamental reason for using pictures in an instructional context is the fact that pictures can serve as carriers of visual information that represents objects and scenes in the environment (Borghi, 2004; Gibson, 1971; Hagen, 1974; Ryan \& Schwartz, 1956). Therefore, they can function as a cognitive aid for learning and instruction (Friedman \& Stevenson, 1980; Hagen, 1980; Mayer 2005a; Watt, 1991). Numerous studies have explored the value of pictures in instruction as well as the information contained in them (e.g., Bieger \& Glock, 1984-85; Booher, 1975; Houts, Doak, Doak, \& Loscalzo, 2006; Szlichcinski, 1979). However, only a few have actually examined how pictorial information conveys functional information for actions. These studies show that pictorial information can convey additional functional information especially when augmented to cue relevant information (Ayres \& Paas, 2007; de Koning, Tabbers, Rikers, \& Paas, 2007; Kurata \& Egenhofer, 2005; Krull \& Sharp, 2006; Lowe \& Pramono, 2006). The present study contributes to extant literature by investigating the effects of augmenting instructions (educational object; Khoshemehr \& Nazemi, 2013) with arrows in a practical assembly and operating task.

Specific to instruction manuals, Agrawala et al.'s (2003) work documented that diagrams can facilitate assembly instructions. Differentiating particular functions of diagrams and their effectiveness in instruction manuals, they suggested that instructional diagrams tend to be of two types; either structural or action diagrams. Although "structural diagrams present all the parts of the assembly in their final 
assembled positions" (Agrawala et al., 2003; p. 829), action diagrams are superior to structural diagrams because they tend to depict similar information found in structural diagrams but with additional action information. Only a few published studies have empirically investigated actual performance indicators that show pictures lead to better performance in instruction manuals (Garnier, Gombert, \& Fayol, 2000, cited in Garnier, 2001; Heiser, Phan, Agrawala, Tversky, \& Hanrahan, 2004). Garnier et al. (2000) documented that it takes longer for people to learn to operate a domestic appliance using a text-only instruction compared to a text and pictures instruction. Heiser et al. (2004) also found that diagrams in instruction manuals facilitated faster assembly between participants who had high versus low spatial ability. However, they did not compare different instructional formats and did not find errors to be a factor between participants who had high versus low spatial ability.

The present study empirically examines the effectiveness of combining text, pictures and arrows augmented onto text-pictorial instructions in assembling and operating a new object. The 3 (text, textpictorial, text-pictorial-arrows) X 2 (picture of object vs. no picture of object) design investigates the ideas behind dual coding theory and the multimedia principle, which posits that words combined with pictures facilitate better learning compared to words alone, since they stimulate active processing (Mayer, Hegarty, Mayer, \& Campbell, 2005) and use different albeit interrelated processing modes (Fletcher \& Tobias, 2005; Mayer 2005b). In short, the present study empirically supports the notion that augmenting pictorial information provides valuable information in instructional settings. In particular, it extends previous works by empirically documenting that arrows can function as attention-directing cues. This paper begins with a brief introduction on the dominance of human visual system, including two cognitive theories that are relevant for learning and instructional interventions. This is followed by a discussion on the significance of augmenting pictures with additional information, which is central to the study; thus leading to the study's hypotheses. The paper then describes the present study's methods, results and concludes with a discussion.

\section{Dominance of human visual system in actions}

Evidence suggests that out of the five sensory modalities, the visual system is most salient in the control of action (Bruce \& Green, 1990; Gibson, 1966, 1979; Rabbitt, 1984; Turvey, 1977; Watt, 1991). In fact, Cutting (1986) argued that all else being equal (i.e., not visually impaired) the visual system dominates other sensory modalities in the process of selecting relevant information, especially when more than one source of information is available. Similarly, when one searches for information via multiple modes, vision is predominantly one of them (Cutting, 1987).

Gibson's (1979) ecological account of visual perception supports the notion that the visual system is a predominant sensory modality for individuals. The ecological approach to visual perception highlights the relationship between available information, perception through the visual system and action (Gibson, 1979). Fundamental to Gibson's account of visual perception is the concept of affordances, which are properties of the environment that support actions (act-on-able) and perceive-able when an active perceptual system is attuned to pick up that information (Gibson, 1966, 1979). To perceive an affordance implies recognizing meaningful aspects of and actionable properties of the environment in relation to one's intention (Garnier, 2001; Kugler \& Turvey, 1987). Therefore, once perceived, affordances may be acted upon if they are compatible with the individual's goal; if not, then they are simply information.

The dominance of the visual system over other perceptual systems in the control of action (for those not visually impaired) and people's ability to pick up affordances implies that human actions can be aided through the presentation of relevant visual information during most tasks. Therefore, one can benefit from visual information that attunes him/her to affordances during a novel activity. For example, research indicates that visual information such as a picture can serve as a goal (Baggett \& Ehrenfeucht, 1988; Norman, 1988) or an explanatory schema that facilitates nonverbal processing (Clark \& Paivio, 1991; Smith \& Goodman, 1984; Sternberg, 2006; Sweller, van Merriënboer, \& Paas, 1998;), as well as reducing the cognitive load on working memory including germane loading (Ayers \& Paas, 2007; de Koning et al., 2007; Sweller, 1998, 2005; Tabbers, Martens, \& van Merriënboer, 2004). The implication is that any technique that reduces load on short-term memory is beneficial in both learning and problem solving situations. As such, scholars prescribe that learning and instructional interventions should include presenting simultaneous information, which can be processed by different processing modes and/or those that produce germane load, that is, processes that are relevant for learning (de Koning, et al., 2007). 


\section{Cognitive processing theories in learning and instructional interventions}

A number of cognitive theories exist which explain how people learn and solve problems. Most of these theories or principles revolve around the limitations of human cognitive capacity and cognition during problem solving. This section discusses two theories that are relevant for learning and instructional interventions; they are dual coding theory and the multimedia principle.

\section{Dual coding theory}

Dual coding theory posits that verbal information such as text is processed via the verbal system while pictorial information is processed through both the verbal and imagery systems. In particular, it posits that verbal and imagery processing systems are "separate but interconnected, so that they can function independently, in parallel, or in an integrated manner" (Sadoski, Paivio, \& Goetz, 2003; p. 473). The implication is that when information is presented in both the verbal (text) and nonverbal (pictorial) modes they are simultaneously processed by two different but interconnected systems that facilitate faster processing and deeper learning of the information (Clark \& Paivio, 1991; Paivio, 1986).

Recent research confirms that compared to text-only, the presence of pictures aids comprehension, recall and recognition; including form- and meaning-based recognition (Houts et al., 2006; Mayer \& Gallini, 1990; Najjar, 1998; Sternberg, 2006). Sternberg (2006) explained that pictures carry information that is functional in orienting task conditions (i.e., structural information), which are stored in both verbal and as nonverbal memory stores. Sternberg's (2006) explanation suggests that including pictures in instructional contexts is useful. In other words, pictures can serve to provide structural information or schema, which are stored in an alternative memory store. As such, this may help to increase one's verbal capacity since the information is now stored in a nonverbal manner, especially in lengthy and complex tasks.

Literature further suggests that presence of pictures during a lengthy complex task facilitates better performance on tasks (Fletcher \& Tobias, 2005; Mayer \& Gallini, 1990; Mayer \& Sims, 1994; Najjar, 1998). From a dual coding perspective, it is logical that if pictures allow parallel processing as opposed to serial or sequential processing of information (Clark \& Paivio, 1991; Seufert, Schütze, \& Brüken, 2009), then parallel and non-competitive processing of information can facilitate faster processing. In turn, cognitive load that would have been used to process information can now be allocated to solve problems. For example, Krull, D'Souza, Roy, and Sharp (2004; p. 28) showed that pictures allow allocentric processing that "enables people to handle relationships centered among objects and identify objects" contained in the pictures. This corroborates Mayer and Gallini's (1990), as well as, Fletcher and Tobias's (2005) work that pictures are most useful for people when they are coupled with understandable text instructions and contain explanatory information; especially for people who lack previous experience on a particular task.

\section{Multimedia principle}

Recent works in the field of multimedia learning (Mayer, 2005a, 2008; Mayer et al., 2005) support dual coding theory and show that multimedia presentation can serve as a cognitive aid in learning situations as well as subsequent transfer tasks (Schmidt-Weigand \& Scheiter, 2011). Specifically, multimedia information helps learners process the information during learning and instructional situations; thus a learner-cantered approach where multimedia aids in developing a schema for learning the materials. Cooper's and Sweller's (1987) work showed that when learners are provided solutions to problems (e.g., goal schema) they tend to learn more than those who were not provided solutions. They argued that those not provided with solutions were taxing their working memory, which interfered with the development of the schemata that would be used to aid learning later (see Sweller, 1988).

Multimedia learning is predicated on similar assumptions to dual coding theory, namely that the "human mind is a dual-channel, limited capacity, active processing system" (Mayer 2005b, p. 37). Therefore, processing of spoken and/or written words and pictures are actively processed using two distinct modes (Fletcher \& Tobias, 2005; Mayer 2005b; Paivio, 1986; Seufert et al., 2009). Empirical evidence indicates that in instructional situations, where words and pictures are provided, it facilitates better learning than words alone (Fletcher \& Tobias, 2005). These works also support cue effect (Severin, 1967) or signalling effect of information. This is the idea that speed of comprehension can be increased when relevant pictorial material or illustrations are presented (Gropper, 1963; Hagen, 1974; Ryan \& Schwartz, 1956) since they cue or attune actors to specific information, such as actions. For example, Garnier (2001) 
found supporting pictures with text improved processing of procedural instructions. He explained that procedural tasks require people to interpret linguistic and pictorial information into motor actions. Garnier argued that since pictorial information contains contextual and structural information, it improved processing of procedural instructions. Moreover, other studies have suggested that augmenting pictures with additional pictorial information, such as arrows, can further help the learning process since arrows cue and/or convey information that guide actions (Ayres \& Paas, 2007; de Koning et al., 2007; Lowe \& Pramono, 2006).

\section{Effectiveness and functions of pictorial information and arrows in instructions}

The field of social semiotics, which has arisen as a critique of mainstream semiotics, views the process of meaning creation as a socially constructed and interactive process. It further posits that in the process of interpretation people choose from a number of possible alternatives when interpreting a sign (Halliday, 1978; Hodge \& Kress, 1988). Since every sign including written text and images used in a communication context can inform the reader about something, interpreting information involves a decision concerning what is the most appropriate meaning or expression in a particular context (Franks \& Jewitt, 2001; van Leuween, 2006). In short, "meaning arises as a consequence of choice and that meaning is multiple" (Jewitt, Kress, Ogborn, \& Tsatsarelis, 2001; p. 6). In addition, most recently there is "an increasing understanding that occasions of communication always draw on a multiplicity of modes of communication at the same time" (Jewitt et al., 2001; p. 6). Hodge and Kress (1988) went as far to suggest that interpretation is effectively an educated guess, although some guesses are better than others. As such, the context in which interpretation occurs is very important to meaning creation for the reader (Franks \& Jewitt, 2001; van Leuween, 2006). The implication is that if the set of signs is presented as instructions to a particular object, then it will be interpreted in relation to the objects and its constituent parts. This semiotic mediation process (Jewitt, 2005) suggests that the interpretation of signs, such as pictures, can be improved if there is additional information to help the reader reach a particular conclusion or outcome.

\section{Pictures as carriers of nonverbal visual information}

Research indicates that pictures convey structural and orienting information (Agrawala et al., 2003; Heiser \& Tversky, 2002; Kurata \& Egenhofer, 2005; Sternberg, 2006) and relationships among objects, which are all useful for guiding human actions (Krull, et al., 2004). Ryan's and Schwartz's (1956) and Hagen's (1974) work showed that illustrations depicting a particular object carried accurate information that specified or identified an object and increased the speed of information acquisition when information depicted in pictures was accentuated or isolated, respectively. Together with recent studies, these suggest that relevant pictorial materials can be modified to accentuate certain aspects of the pictures to facilitate learning, including clarifying meanings such as the internal and external dynamics of the depicted object (Agrawala et al., 2003; Heiser \& Tversky, 2002; Horton, 1994; Krull \& Sharp, 2006; Kurata \& Egenhofer, 2005; Najjar, 1998; Thom, 1975). At the same time, augmenting pictures with arrows can convey additional information to readers, such as causation, direction, relational information, movement, and sequence (Agrawala et al. 2003; Heiser \& Tversky, 2002; Lowe \& Pramono, 2006; de Koning et al., 2007; Tversky, Zacks, Lee, \& Heiser, 2000).

\section{Arrows as pictorial and carriers of action information}

One of the functions that arrows play in instructions is to attune people to affordance properties of an object since people do not readily perceive actionable properties from pictures because functions of objects are not readily interpreted from the information depicted in pictures (Heiser \& Tversky, 2002; Tversky et al., 2000). For example, Garnier's (2001) and Hegarty's (1992) work showed that even if people can pick up affordances from diagrams and pictures, they do not act upon them unless they are guided by the instructions. Taken together, these findings suggest that augmenting pictures and/or diagrams with arrows serves to highlight affordances of an object, including its functions and other relevant information about the object. At the same time, arrows may also serve to function as attentiondirecting cues for the user of the information (Kalyuga, 2012). 


\section{Semantic meanings of arrows}

Kurata's and Egenhofer's (2005) work identified a number of meanings from arrows depending on their usage in relation to the pictures or diagrams. One meaning from arrows is movement when used in relation to locations in a picture or diagram (de Koning, et al., 2007; Hegarty, 1992; Horton, 1994; Krull \& Sharp, 2006). If several arrows link geographical regions together with start- and end-points, then it can indicate causality or direction of movement. For example, when an arrow is used to link an object to another object or a location then it "is always interpreted uniquely as movement of the object to the location" (Kurata \& Egenhofer, 2005; p. 3) or towards the other object. They argued that the direction of the objects coupled with arrows convey relationship and/or movement between the objects. In other words, the meanings of the arrows are interpreted in relation to other elements in the diagram or picture (Lowe \& Pramono, 2006) that are processed via the imagery and/or nonverbal system.

Other works indicate similar meanings and functions of arrows in instruction manuals. Heiser and Tversky (2002) argued that since diagrams contain structural and typological information, arrows could indicate sequences of operations. Similarly, Garnier's (2001) work confirmed that supporting pictures with text conveys sequential information in procedural instructions and improve its processing. Another set of studies illustrated that arrows can provide users with information that indicate movement of parts (Szlichcinski, 1979; Tversky et al., 2000) and actions (Krull \& Sharp, 2006; Szlichcinski, 1979), including directions for actions (see Rasmussen, 1983) and final positions of components.

In summary, Agrawala et al.'s (2003) work showed that action diagrams, which included arrows, are superior structural diagrams compared to those that do not contain arrows. Furthermore, they showed that arrows also function to attune readers to relevant information in the instructions. For example, arrows can point to parts on the actual object that are obscured in the diagrams or pictures (de Koning et al., 2007) thus functioning as attention-directing cues for users (Kalyuga, 2012). The above discussion, therefore, implies that coupling pictures and arrows in instructional objects provides information that guides actions in procedural tasks, as well as a more user-friendly knowledge environment since it facilitates the learnercontent interaction (Kanuka, 2011; Khoshemehr \& Nazemi, 2013). This implication leads to a number of predictions in the present study.

\section{The present study}

This study empirically examined the effectiveness of combining text-pictorial and arrows augmented onto text-pictorial instructions in assembly instructions and the operation of a novel object after assembly. It also examined whether a picture of the assembled object (all the parts in their final assembled positions) aided assembly and operation of the object. The study operationalized efficient and better performance if learners could perform the task faster with the least amount of errors and/or extra procedures on the tasks. The study used a 3 (text, text-pictorial, text-pictorial-arrows) X 2 (picture of object vs. no picture of object) design to investigate how each of the four information types facilitated performance in six conditions. They are as follows: text-only; text with a picture of the assembled object; text-pictorial; textpictorial with a picture of the assembled object; text-pictorial-arrows; and text-pictorial-arrows with a picture of the assembled object. Two hypotheses are presented for the study.

\section{Hypotheses}

Sternberg (2006) claimed that pictures are in effect carriers of structural information, which function to orient learners during a learning process. Discussions in previous sections established that pictorial information in instructions enhance recall and recognition of information related to the task (Mayer \& Gallini, 1990; Najjar, 1998; Sternberg, 2006). It was documented that text-pictorial information supported procedural tasks since it aided learners to interpret linguistic and pictorial information into motor actions (Garnier, 2001). Recent works also suggest that pictures can convey structural and orienting information, and how depicted objects relate to one another (Agrawala et al., 2003; Heiser \& Tversky, 2002; Krull, et al., 2004; Kurata \& Egenhofer, 2005; Sternberg, 2006), which all can be used to support actions in novel situations and/or when no other pictorial information is available. In short, the combined information sets will provide users with structural information informing them how the depicted objects relate to each other thus facilitating better performance. Based on these previous works, this study predicts the following: 
Hypothesis 1A. Presenting a picture of the assembled object in assembly instructions provides users with useful visual information, which facilitates efficiency and accuracy in assembly and operation of objects.

Hypothesis 1B. Presenting step-by-step pictures in assembly instructions facilitates efficiency and accuracy in assembly and operation of objects.

Previous discussions suggest that augmentation of pictorial information with arrows can provide readers with information that indicates movement (de Koning, et al., 2007; Hegarty, 1992; Horton, 1994; Krull \& Sharp, 2006), movement of parts (Szlichcinski, 1979; Tversky et al., 2000) and actions (Krull \& Sharp, 2006; Szlichcinski, 1979). Recent works also point to the idea that pictorial information that implies movement or action (Agrawala et al., 2003), direction of movement (Lowe \& Pramono, 2006), or attunes readers to relevant information in instructions (i.e., cueing - de Koning et al., 2007) leads to better interpretation comprehension and cognitive performance of transfer task (de Koning et al., 2007; SchmidtWeigand \& Scheiter, 2011). Based on these findings, the present study predicts the following:

Hypothesis 2. Use of arrows with pictures in assembly instructions attunes users to relevant information concerning the object to assemble, including directions and movements that guide actions, which facilitates efficiency and accuracy during assembly and operation of objects.

\section{Method}

\section{Sample}

The sample was drawn from an undergraduate psychology student population at a large university in New Zealand. Sixty-six participants volunteered to take part in the study, 59\% of the participants were females. As an incentive scheme, participants were entered into a draw for grocery vouchers; however, participants did not receive course credit. Their ages ranged from 17 to 50 years. Participants were randomly assigned to six experimental conditions. Each condition varied on the type of information participants received in the instruction manuals. There were six conditions with the following female percentage: 1) 64\%; 2) $55 \%$; 3) $55 \%$; 4) $55 \%$; 5) $64 \%$; 6) $64 \%$. 29 participants also took part in the development of the experiment, 8 were in the exploratory study, 16 in pre-pilot testing and 5 for the pilot study. None of the data from the exploratory, pre-pilot and pilot studies were used in the analyses. The pilots were conducted to test if the instructions and arrangements were adequate for the experiment.

\section{Materials}

A portable Continuous Passive Motion Hand unit (the designers called it the CPM) was used as the assembly and operating task. The CPM is a lightweight exercise device designed to stimulate healing and regeneration of the flexor and extensor muscles of a patient's hand; please refer to Picture 1 (CPM picture) in Appendix 1. Performance on the assembly and operating task was timed and recorded on video to allow for coding. A performance classification scheme was used to categorize each participant's behaviours during assembly and operating tasks from the video; please refer to Appendix 5 and 6 . Participants' behaviours were the dependent variables for the study, which included: incorrect procedures, incorrect procedures during operation of CPM, extra procedures, extra procedures during operation of CPM, omitted procedures, omitted procedures during operation of CPM, reference to glossary, reference to glossary during operation of CPM, unsuccessful assembly, assembly time, time during operation of CPM, total performance time and utility ratings of glossary for CPM parts.

A task analysis of the assembly and operating procedure was conducted by observing and recording the procedures performed by a technician on the design team and the designer. Instructions were developed from the task analysis and the aid of existing guidelines (Bieger \& Glock, 1984-85; Booher, 1975; Braby, Kincaid, \& McDaniel, 1982; Dixon, 1982; Hegarty, 1992; Hodgkinson \& Hughes, 1982; Horton, 1994; Krull \& Sharp, 2006; Kurata \& Egenhofer, 2005; Nailen, 1981; Resnick, 1976; Stone \& Glock, 1981; Szlichcinski, 1979; Tversky, et al., 2000). Six different instruction manuals were produced to coincide with the six experimental conditions in the study: 1) Text, 2) Text and CPM picture (picture of CPM with all the parts in their final assembled positions), 3) Text-Pictorial, 4) Text-Pictorial and CPM picture, 5) Text-Pictorial-Arrows, 6) Text-Pictorial-Arrows and CPM picture. The printed words component was identical for all six formats. 
Appendix 1 shows an example of the text format in the first six pages of the manuals. All the text was identical in all conditions. Relevant step-by-step pictures were then added; the step-by-step pictures were identical for manuals 3, 4, 5, and 6. Specific arrows were then added to manuals 5 and 6 to point to parts and locations on the CPM, and convey directions of actions including movement. Please refer to Appendix 3 for an example of the pictorial information, and arrows augmentation and format of the manuals.

Pilot studies were conducted to validate the adequacy of the Text manual. Adequacy was defined as the consistent and successful assembly of the CPM within a time limit of 60 minutes. Five pilot tests were conducted and results indicated that the text-instructions were able to aid participants to perform the task within a 60-minute time limit.

\section{Procedures}

Participants were randomly assigned to the six experimental conditions. Each participant assembled and operated the CPM. Components of the CPM were presented in a pre-arranged convention as presented in the "Names of CPM parts" in Appendix 1. Each participant was instructed to assemble the unit "as fast and as accurately as possible" using the manual. On successful completion of the assembly task, participants were required to operate the CPM (operating task). Participants who did not correctly assemble the CPM were asked to correct the assembly via written instructions and feedback; "You have failed to assemble the product correctly, please correct the error(s)".

Once the assembly and operation of the CPM were completed, participants were then asked to rate the utility of the glossary in the instruction manuals. In addition, participants were asked if they had seen the CPM prior to the experiment. None reported having previously seen the unit. All participants were asked not to discuss the experiment with their friends and colleagues.

The experimenter and a trained volunteer coded the videos; however, the volunteer rater had no knowledge of the treatment conditions (Crandell, 1979) and/or hypotheses. The two raters coded each performance simultaneously, but independently with a barrier between them so that they could not see each other. Upon completion of the rating process, the numbers of performance behaviours in each category were tallied. A comparison of the rating between the two raters was made. If the ratings were different, it was noted to record inter-rater reliability. Out of a possible 1,122 points of observations, the present study had an inter-rater reliability of 99.6. A copy of the performance classifications for coding the tasks are found in Appendix 5.

The time participants took to perform the tasks was measured using two different stopwatches during the coding process. The volunteer rater monitored the time performances with the same digital stopwatch used during the experimental sessions while the experimenter used an alternate stopwatch during the rating sessions; resulting in three sets of time measurement being taken. In all cases, the times fell within less than 2 seconds of each other.

\section{Results}

To examine effects of the information manipulations and test hypotheses $1 \mathrm{~A}, 1 \mathrm{~B}$ and 2 , a $3 \mathrm{X} 2$ MANOVA was conducted. The independent variables were Instruction Conditions (Text, Text-Pictorial, Text-Pictorial-Arrows) and a picture of assembled product (Presence or Absence of CPM picture). The dependent variables were incorrect procedures, incorrect procedures during operation of CPM, extra procedures, extra procedures during operation of CPM, omitted procedures, omitted procedures during operation of CPM, reference to glossary, reference to glossary during operation of CPM, unsuccessful assembly, assembly time, time during operation of CPM, total performance time and utility ratings of glossary for CPM parts. Results showed a main effect for Instruction Conditions $F(26$, 96; Wilks Lambda $)=5.68, p<.001$; and CPM picture $F(13,48$; Wilks Lambda $)=6.02, p<.001$; plus an interaction effect $F(26,96$; Wilks Lambda $)=3.28, p<.001$. Univariate statistics are found in Table 1 . To examine hypothesis $1 \mathrm{~A}$ further, within-conditions post-hoc comparisons (i.e., comparing instructions with a picture of CPM and its absence within the three different conditions) were performed; please refer to Table 1. Similarly, to further examine hypothesis 1B and 2, between group post-hoc comparisons amongst instruction conditions in the absence and presence of CPM picture conditions were performed; please refer to Table 2 and 3 respectively. 
Table 1.

Mean performance comparisons using three different instruction formats with no picture vs. a picture of assembled object

\begin{tabular}{|c|c|c|c|c|c|c|c|c|c|c|}
\hline \multirow[b]{2}{*}{ Variables } & \multirow[t]{2}{*}{$\begin{array}{l}\text { Manual } \\
F(2,60)\end{array}$} & \multirow[t]{2}{*}{$\begin{array}{l}\text { Pic. CPM } \\
F(1,60)\end{array}$} & \multirow{2}{*}{$\begin{array}{l}\text { Manual X } \\
\text { Pic. CPM } \\
F(2,60)\end{array}$} & \multicolumn{7}{|c|}{ Means and Standard Deviation } \\
\hline & & & & & Text & $S D$ & $\begin{array}{l}\text { Text- } \\
\text { Pictorial } \\
\end{array}$ & $S D$ & $\begin{array}{l}\text { Text-Pictorial- } \\
\text { Arrows } \\
\end{array}$ & $S D$ \\
\hline \multirow[t]{2}{*}{ incorrect procedures (IP) } & $27.94 * * *$ & $5.92 *$ & $6.21 * *$ & No Pic. & 19.9 & 9.19 & 4.5 & 3.78 & 3.5 & 1.69 \\
\hline & & & & Pic. CPM & 9.7 & 6.39 & 5.4 & 6.22 & 2.6 & 2.83 \\
\hline \multirow{2}{*}{$\begin{array}{l}\text { incorrect procedures } \\
\text { during op. of CPM (IPO) }\end{array}$} & $3.63^{*}$ & 2.32 & 1.84 & No Pic. & 5 & 2.14 & 3.1 & 2.95 & 2.1 & 1.70 \\
\hline & & & & Pic. CPM & 2.7 & 2.2 & 2.9 & 2.07 & 2.1 & 1.81 \\
\hline extra procedures $(\mathrm{EP})$ & & & & Pic. CPM & 4.5 & 2.25 & 2.4 & 2.25 & 1.7 & 1.19 \\
\hline \multirow{2}{*}{$\begin{array}{l}\text { extra procedures } \\
\text { during op. of CPM (EPO) }\end{array}$} & $4.37 *$ & 2.58 & .68 & No Pic. & 2.1 & 1.97 & 1.1 & 1.14 & 1.0 & .70 \\
\hline & & & & Pic. CPM & 1.3 & 1.27 & 1.1 & 1.14 & .3 & .65 \\
\hline \multirow[t]{2}{*}{ omitted procedures (OP) } & 2.63 & $5.04 *$ & .65 & No Pic. & .9 & 1.57 & 1.0 & 1.41 & .2 & .40 \\
\hline & & & & Pic. CPM & .09 & .30 & .5 & .69 & 0.0 & .00 \\
\hline \multirow{2}{*}{$\begin{array}{l}\text { omitted procedures } \\
\text { during op. of CPM (OPO) }\end{array}$} & 1.49 & 1.12 & .09 & No Pic. & .7 & 1.0 & .5 & .52 & .2 & .40 \\
\hline & & & & Pic. CPM & 1.3 & 2.6 & .8 & 1.78 & .4 & .50 \\
\hline \multirow{2}{*}{$\begin{array}{l}\text { reference to glossary } \\
\text { for CPM parts (RG) }\end{array}$} & $33.66 * * *$ & 2.25 & 2.4 & No Pic. & 17.6 & 7.65 & 8.3 & 5.13 & 1.6 & 3.80 \\
\hline & & & & Pic. CPM & 11.6 & 5.61 & 9.5 & 7.43 & .2 & .40 \\
\hline $\begin{array}{l}\text { reference to glossary } \\
\text { during op. of CPM (RGO) }\end{array}$ & & & & Pic. CPM & 1.4 & 1.96 & .6 & .81 & 0.0 & .00 \\
\hline \multirow{2}{*}{$\begin{array}{l}\text { unsuccessful } \\
\text { assembly (UA) }\end{array}$} & $9.52 * * *$ & $11.22 * *$ & 1.57 & No Pic. & 1.3 & .90 & .5 & .69 & .3 & .47 \\
\hline & & & & Pic. CPM & .5 & .69 & .1 & .30 & 0.0 & 00 \\
\hline \multirow[t]{2}{*}{ assembly time (AT) } & $31.94 * * *$ & $3.55^{\mathrm{a}}$ & 2.86 & No Pic. & 3891.4 & 1148.9 & 2074.2 & 314.43 & 1868.6 & 626.61 \\
\hline & & & & Pic. CPM & 2978.5 & 898.54 & 2200.1 & 706.84 & 1637.0 & 304.85 \\
\hline \multirow{2}{*}{$\begin{array}{l}\text { time during op. of CPM } \\
\text { (TO) }\end{array}$} & $6.76^{* *}$ & .66 & .15 & No Pic. & 878.7 & 227.44 & 708.5 & 217.58 & 683.9 & 273.3 \\
\hline & & & & Pic. CPM & 864.5 & 251.28 & 676.5 & 194.05 & 599.8 & 101.11 \\
\hline \multirow{2}{*}{$\begin{array}{l}\text { total performance } \\
\text { time (TPT) }\end{array}$} & $30.36 * * *$ & $3.35^{\mathbf{b}}$ & 1.61 & No Pic. & 5341.0 & 1299.11 & 3317.0 & 463.76 & 3031.7 & 854.95 \\
\hline & & & & Pic. CPM & 4413.8 & 1198.50 & 3339.0 & 712.36 & 2730.5 & 440.78 \\
\hline \multirow{2}{*}{$\begin{array}{l}\text { utility ratings of } \\
\text { glossary for CPM parts (UG) }\end{array}$} & $18.56^{* * *}$ & $45.4 * * *$ & $35.02 * * *$ & No Pic. & 0.0 & 0.0 & 4.5 & 1.51 & 3.1 & 1.81 \\
\hline & & & & Pic. CPM & 5.9 & 1.22 & 5.5 & 1.57 & 2.6 & .92 \\
\hline
\end{tabular}

Note. 1$)^{*}=p<.05 ; * *=p<.01 ; * * *=p<.001 .2$ ) Bold, italicized means within the Text group indicate significance between two means at $p<.05$; the other two showed no withingroup effects between for Picture of CPM. 3) Times are in seconds. 


\section{Effect of pictorial information on assembly and operating performance}

Comparisons of performance using Text versus Text-Pictorial manuals (without CPM picture) showed that the Text-Pictorial manual improved performance during assembly and operation of CPM. Participants using Text-Pictorial without CPM picture manual had fewer: incorrect procedures, extra procedures, references to the glossary during assembly and operation of CPM, unsuccessful assemblies. They were faster in assembling the CPM, i.e., assembly time, overall faster, i.e., total performance time, and rated the glossary for CPM parts, i.e., utility rating of glossary more useful than participants using the Text only manual did. Please refer to Table 2 for mean comparisons between the Text, Text-Pictorial and Text-Pictorial-Arrows conditions without CPM picture.

Performance comparisons using Text versus Text-Pictorial manuals (with CPM picture) also showed that the latter improved performance during assembly and operation of CPM. Participants using Text-Pictorial with CPM picture manual had fewer: extra procedures, references to the glossary for CPM parts. They were faster in assembling and operating the CPM, and were faster overall. Please refer to Table 3 for comparisons between the Text, Text-Pictorial and Text-Pictorial-Arrows conditions with CPM picture.

To test the effect of adding the CPM picture within conditions, additional post-hoc MANOVA was conducted to compare performances within the Text, Text-Pictorial, and Text-Pictorial-Arrows conditions. Results showed significant effect for Instruction Conditions (All 6) F(49, 60; Wilks Lambda) $=3.53, p<.001$. Multiple comparisons showed the presence of the CPM picture (Picture 1) significantly improved performance but only in the Text condition. Overall, presence of CPM picture improved performance in all categories except for the number of procedures omitted during operation of CPM.

In short, providing participants with a CPM picture in what was a text only manual improved participants' efficiency and accuracy during assembly and operation of object. Participants had fewer: incorrect procedures, extra procedures, omitted procedures and references to the glossary compared to those without the CPM picture. Those who received the CPM picture were faster during assembly and in the overall performance (AT, TPT); most importantly, they significantly had fewer unsuccessful assemblies (UA) of the CPM. Finally, participants who received the CPM picture rated the utility of glossary for CPM parts (UG) higher than those who did not receive the CPM picture. Refer to Table 1 for mean scores within each condition. Note that all the significant effects within conditions were at $p<.05$ or better, they are listed as .05 to maintain clarity of the table.

These findings suggest that a picture of the assembled object did improve performance, in general support of dual coding theory and the multimedia principle, as well as hypotheses $1 \mathrm{~A}, 1 \mathrm{~B}$ and 2 . In summary, adding a picture and step-by-step pictures reduced errors and extra procedures, enabled one to perform the task faster and most importantly, aided the correction of one's errors during the task when using the pictorial and arrows manual in the presence of the CPM picture.

Patterns of redundancy were found since the addition of the CPM picture no longer showed improvements in the performances of those using manuals that contained pictorial and arrows information. Further, there may have been some interference effects although they were not significant, i.e., assembly and operating times were slower, as well as participants making more errors, but only in the text-pictorial condition and not in the text-pictorial-arrows condition.

A post-hoc ANOVA was carried out between groups that received a picture of CPM to test the number of times participants referred to the picture (See Appendix 6; Reference to CPM picture during assembly). There was a between group effect $F(2,30)=6.0, p<.001$. Comparisons showed that participants in the text condition $(m=3.2)$ referred to the picture significantly more $(p<.05)$ than those in the text-pictorial $(m=.9)$ and text-pictorial-arrows condition $(m=.09)$. 
Table 2

Mean performance comparisons in text, text-pictorial and text-pictorial-arrows formats without CPM picture

\begin{tabular}{|c|c|c|c|c|}
\hline Condition & $\begin{array}{l}\text { Manual } \\
F(2,30)\end{array}$ & $M$ Text & $\begin{array}{l}M \text { Text- } \\
\text { Pictorial }\end{array}$ & $\begin{array}{l}M \text { Text-Pictorial- } \\
\text { Arrows }\end{array}$ \\
\hline incorrect procedures (IP) & $27.63 * * *$ & $19.9^{\text {a b }}$ & $4.5^{\mathrm{a}}$ & $3.5^{\mathrm{b}}$ \\
\hline incorrect procedures during op. of CPM (IPO) & $4.45^{*}$ & $5^{a}$ & 3.1 & $2.1^{\mathrm{a}}$ \\
\hline extra procedure $(\mathrm{EP}) \mathrm{s}$ & $13.52 * * *$ & $7.3^{\mathbf{a b}}$ & $2.0^{\mathrm{a}}$ & $1.4^{\mathrm{b}}$ \\
\hline extra procedures during op. of CPM (EPO) & 2.36 & 2.1 & 1.1 & 1.0 \\
\hline omitted procedures $(\mathrm{OP})$ & 1.43 & 0.9 & 1.0 & 0.2 \\
\hline omitted procedures during op. of CPM (OPO) & 1.68 & 0.7 & 0.5 & 0.2 \\
\hline reference to glossary for CPM parts (RG) & $21.43 * * *$ & $17.6^{\mathbf{a b}}$ & $8.3^{\text {a c }}$ & $1.6^{\mathbf{b c}}$ \\
\hline reference to glossary during op. of CPM (RGO) & $5.87 * *$ & $2.8^{\mathbf{a ~ b}}$ & $0.8^{\mathrm{a}}$ & $0.1^{\mathbf{b}}$ \\
\hline unsuccessful assembly (UA) & $6.21 * *$ & $1.3^{\mathbf{a b}}$ & $0.5^{\mathrm{a}}$ & $0.3^{\mathbf{b}}$ \\
\hline assembly time (AT) & $22.58 * * *$ & $3891.4^{\mathbf{a ~ b}}$ & $2074.2^{\mathrm{a}}$ & $1868.6^{\mathbf{b}}$ \\
\hline time during op. of CPM (TO) & 2.14 & 878.7 & 708.5 & 683.9 \\
\hline total performance time (TPT) & $19.86^{* * *}$ & $5341.0^{\mathbf{a b}}$ & $3317.0^{\mathrm{a}}$ & $3031.7^{\mathbf{b}}$ \\
\hline utility ratings of glossary for CPM parts (UG) & $30.90 * * *$ & $0.0^{\mathbf{a b}}$ & $4.5^{\mathrm{ac}}$ & $3.1^{\mathbf{b c}}$ \\
\hline
\end{tabular}

Note. $*=p<.05 ; * *=p<.01 ; * * *=p<.001$. Superscripted letters indicate significance between same letter groups at $p<.05$. Times are in seconds, and all standard deviation for means are the same as in Table 1.

\section{Effect of pictorial information and arrows on assembly and operating performance}

Performance using Text versus Text-Pictorial-Arrows manuals without CPM picture revealed similar performance improvements during assembly and operation of CPM as observed previously comparing Text only with other manuals (Table 2). Participants using Text-Pictorial-Arrows had fewer: incorrect procedures (IP, IPO), extra procedures (EP, EPO), and references to the glossary for CPM parts (RG, RGO). They were faster in the assembly of CPM compared to participants using Text only. Again, overall, those using Text-Pictorial-Arrows manual were faster and had fewer numbers of unsuccessful assembly compared to those using Text only.

Comparisons of performance using Text versus Text-Pictorial-Arrows manuals with CPM picture showed the latter improved performance during assembly and operation of CPM but with fewer effects (Table 3). Participants using Text-Pictorial-Arrows had fewer: incorrect procedures, extra procedures (EP, EPO), references to the glossary for CPM parts (RG) and were faster in the assembly of CPM (AT) including faster operation of CPM (TO) compared to participants in the Text conditions. Overall, those using Text-Pictorial-Arrows were faster and had fewer numbers of unsuccessful assemblies compared to those using the Text manual. These results support the multimedia principle, dual coding theory and hypothesis 2; that is, augmenting pictures with arrows can aid the instruction process and actions during practical tasks.

Results showed that when a picture of CPM was present, the Text-Pictorial information might have become redundant since the significant effects were reduced. However, findings showed that overall, those using the Text-Pictorial manual still had fewer errors, were faster and most importantly had fewer instances of unsuccessful assembly compared to those using the Text-Only manual. 
Table 3.

Mean performance comparisons in text, text-pictorial and text-pictorial-arrows formats with CPM picture.

\begin{tabular}{|c|c|c|c|c|}
\hline $\begin{array}{ll}\text { Variables } & \text { Condition } \\
\end{array}$ & $\begin{array}{l}\text { Manual } \\
F(2,30)\end{array}$ & $\begin{array}{l}M \text { Text- } \\
\text { CPM }\end{array}$ & $\begin{array}{c}M \text { Text- } \\
\text { Pictorial- } \\
\text { CPM }\end{array}$ & $\begin{array}{l}M \text { Text-Pictorial- } \\
\text { Arrows-CPM }\end{array}$ \\
\hline incorrect procedures (IP) & $4.82 * *$ & $9.7^{\mathrm{a}}$ & 5.4 & $2.6^{\mathrm{a}}$ \\
\hline incorrect procedures during op. of CPM (IPO) & 0.5 & 2.7 & 2.9 & 2.1 \\
\hline extra procedures $(\mathrm{EP})$ & $5.12 * *$ & $4.5^{\mathrm{ab}}$ & $2.4^{\mathrm{a}}$ & $1.7^{\mathrm{b}}$ \\
\hline extra procedures during op. of CPM (EPO) & 2.81 & $1.3^{\mathrm{a}}$ & 1.1 & $.3^{\mathrm{a}}$ \\
\hline omitted procedures $(\mathrm{OP})$ & $3.39 *$ & .09 & $.5^{\mathrm{a}}$ & $0.0^{\mathrm{a}}$ \\
\hline omitted procedures during op. of CPM (OPO) & 0.67 & 1.3 & 0.8 & 0.4 \\
\hline reference to glossary for CPM parts (RG) & $14.13 * * *$ & $11.6^{\mathrm{a}}$ & $9.5^{\mathbf{a b}}$ & $0.2^{\mathbf{b}}$ \\
\hline reference to glossary during op. of CPM (RGO) & $3.41 *$ & $1.4^{\mathrm{a}}$ & 0.6 & $0.0^{\mathrm{a}}$ \\
\hline unsuccessful assembly (UA) & $3.38^{*}$ & $0.5^{\mathrm{a}}$ & 0.1 & $0.0^{\mathrm{a}}$ \\
\hline assembly time (AT) & $10.70 * * *$ & $2978.5^{\mathbf{a b}}$ & $2200.1^{\mathrm{a}}$ & $1637.0^{\mathbf{b}}$ \\
\hline time during op. of CPM (TO) & $5.52 * *$ & $864.5^{\mathbf{a b}}$ & $676.5^{\mathrm{a}}$ & $599.8^{\mathbf{b}}$ \\
\hline total performance time TPT() & $11.21 * * *$ & $4413.8^{\text {a b }}$ & $3339.0^{\mathrm{a}}$ & $2730.5^{\mathrm{b}}$ \\
\hline utility ratings of glossary for CPM parts (UG) & $22.04 * * *$ & $5.9^{\mathrm{a}}$ & $5.5^{\mathrm{b}}$ & $2.6^{\mathbf{a b}}$ \\
\hline
\end{tabular}

Note. ${ }^{*}=p<.05 ; * *=p<.01 ; * * *=p<.001$. Superscripted letters indicate significance between same letter groups at $p<.05$. Times are in seconds.

These results illustrate the multimedia effect; that is, instructional situations that combine words with pictures facilitate better instructions evidenced by superior performance in conditions that had at least one picture in both assembly and operation task. The latter effect does indicate that there are some benefits in having pictures during subsequent task performance compared to performance using words alone. The results also provide support for dual coding theory as well as hypotheses $1 \mathrm{~A}$ and $1 \mathrm{~B}$. It is interesting that participants in the Text-Pictorial condition rated the value of the glossary for CPM parts higher than those in the Text condition (including the operation phase) but actually used it less. This may reflect participants' perception of the glossary for CPM parts and the picture as aspects of the manual that helped the instruction process during the assembly and operation, and as a result they rated the glossary for CPM parts as more useful in the Text-Pictorial manual compared to the Text only manual.

\section{Effect of arrows on assembly and operating performance}

Performance comparisons using Text-Pictorial without CPM picture versus Text-Pictorial-Arrows condition without CPM picture indicated a redundancy effect of the step-by-step pictures since the latter showed few performance improvements. However, participants using the Text-Pictorial-Arrows manual did have fewer references to the glossary during assembly and rated the utility of glossary for CPM parts lower compared to those using the Text-Pictorial manual (Table 2).

Performance using Text-Pictorial with CPM picture versus Text-Pictorial-Arrows with CPM picture manuals continued to indicate redundancy effect of the step-by-step pictures. That said, participants using Text-Pictorial-Arrows manual still had fewer omitted procedures (OP), references to glossary (RG) during assembly, and rated the utility of glossary for CPM parts (UG) lower compared to those using Text-Pictorial manual (refer to Table 2).

Results again indicate some redundancy effects where the influences of augmenting arrows onto text with step-by-step information were minimal. Notwithstanding the redundancy effect, the mean scores indicate improvements in performance when participants used the text and step-by-step pictures augmented with arrows manual compared to those using the text and step-by-step pictures manual. These results still support the multimedia principle, and hypothesis 2 ; in short, the presence of arrows did improve 
performance. It is possible therefore that the presence of arrows provided participants with contextual, structural and movement information so that they were able to process the instructions faster and more effectively thus not miss any steps. The fact that pictorial-arrows information led to fewer errors of omission is a contribution to extant knowledge on instructions for procedural tasks.

Interaction effect of picture of assembled object on assembly and operating performance

Multiple comparisons of performance during assembly and operation of CPM between the Text, TextPictorial and Text-Pictorial-Arrows conditions by absence versus presence of CPM picture revealed two significant interaction effects for incorrect procedures during assembly and utility of glossary for CPM parts (see Table 1 as well as Figures 1 and 2). The interaction effect for perceived utility of glossary for CPM parts does not indicate an interference effect, but rather a multimedia effect since the pattern indicates lower ratings of glossary for CPM parts as pictures and arrows were added to the instructions manuals.



Figure 1. Interaction effect for number of incorrect procedures during assemly.

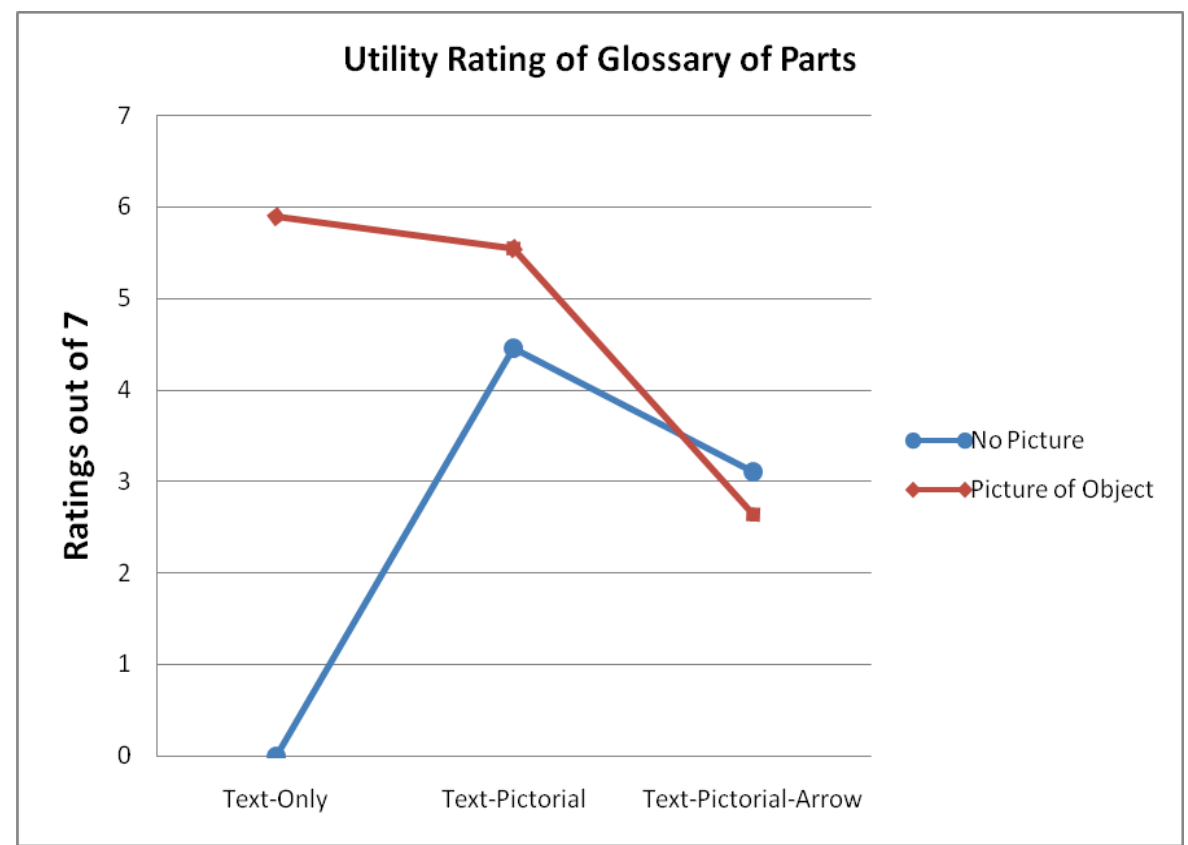

Figure 2. Interaction effect for utility ratings of glossary for CPM parts. 
The higher number of incorrect procedures exhibited when the CPM picture was added to the TextPictorial condition does indicate an interference effect; however, the increased number of incorrect procedures was only slight and not significant within the Text-Pictorial condition. Further, this interaction effect was found only in one of the eight action-oriented performance categories (Table 1). As such, these patterns do not support significant interference effect.

\section{Post-hoc regression analysis}

To explore effects of performance behaviours on assembly and operation two separate regressions were conducted. Assembly time was set as the dependent variable and the following performance indicators as independent variables: incorrect procedures, extra procedures, omitted procedures, reference to glossary for CPM parts, and unsuccessful assembly. The same independent variables were used for the operation of CPM; except, operation time was used as the dependent variable and whether operation was unsuccessful. Tables $4 \mathrm{a}$ and $4 \mathrm{~b}$ indicate that multicollinearity was not present amongst the performance indicators since all the tolerance indices were above .10 and variance inflation factors were all well below 10 (Cooper and Schindler, 2003; Everitt, 1996; Kleinbaum, Kupper, \& Muller, 1988).

Results showed incorrect procedures (IP), extra procedures (EP), and reference to glossary for CPM parts (RG) were significant predictors of time taken to assemble the CPM, accounting for $83 \%$ of the variability (Table 4a). These results suggest that the length of time to assemble became longer as participants made more incorrect, extra procedures and reference to glossary for CPM parts. Results also indicated incorrect procedures (IPO) and references to glossary (RGO) were a significant predictor of time taken to operate the CPM; accounting for $40 \%$ of the variability (Table 4b). As such, it took participants longer to test and operate the CPM as they made more errors and references to the glossary for CPM parts.

Table 4a

Performance indicators to assembly times regression analysis

\begin{tabular}{lllll}
\hline \multicolumn{1}{c}{ Variable } & $B$ & $\mathrm{~B}$ & $t$ & Overall statistics \\
\hline incorrect procedures (IP) & 27.232 & .210 & $2.46^{*}$ & Multiple $R=.92$ \\
extra procedures (EP) & 126.472 & .384 & $5.65^{* * *}$ & $R^{2}=.84$ \\
$\begin{array}{l}\text { omitted procedures (OP) } \\
\text { reference to glossary for CPM }\end{array}$ & -83.357 & -.078 & -1.42 & Adjusted $R^{2}=.83$ \\
parts (RG) & 52.332 & .401 & $5.84^{* * *}$ & $F=63.07^{* * *}$ \\
unsuccessful assembly (UA) & 200.097 & .134 & 1.91 & \\
\hline
\end{tabular}

\begin{tabular}{|c|c|c|c|c|}
\hline \multicolumn{5}{|l|}{ Collinearity Diagnostics } \\
\hline Variable & Eigenvalue & Tolerance & VIF & $\begin{array}{l}\text { Condition } \\
\text { Index }\end{array}$ \\
\hline incorrect procedures (IP) & .772 & .367 & 2.725 & 2.301 \\
\hline extra procedures $(\mathrm{EP})$ & .495 & .578 & 1.731 & 2.873 \\
\hline omitted procedures (OP) & .274 & .886 & 1.129 & 3.864 \\
\hline $\begin{array}{l}\text { reference to glossary for CPM } \\
\text { parts (RG) }\end{array}$ & .232 & .566 & 1.768 & 4.199 \\
\hline unsuccessful assembly (UA) & .139 & .538 & 1.858 & 5.415 \\
\hline
\end{tabular}


Table $4 \mathrm{~b}$

Performance indicators to assembly performance regression analysis.

\begin{tabular}{|c|c|c|c|c|}
\hline Variable & $B$ & B & $t$ & Overall statistics \\
\hline incorrect procedures during op. of CPM (IPO) & 46.282 & .460 & $4.187 * * *$ & Multiple $R=.66$ \\
\hline extra procedures during op. of CPM (EPO) & -1.080 & -.006 & -.051 & $R^{2}=.44$ \\
\hline omitted procedures during op. of CPM (OPO) & 16.069 & .096 & .919 & Adjusted $R^{2}=.40$ \\
\hline reference to glossary during op. of CPM (RGO) & 54.318 & .425 & $4.239 * * *$ & $F=12.01 * * *$ \\
\hline
\end{tabular}

Note. $* p<.05 ; * * p<.01 ; * * * p<.001$.

Collinearity Diagnostics

\begin{tabular}{llccc}
\hline \multicolumn{1}{c}{ Variable } & Eigenvalue & Tolerance & VIF & $\begin{array}{c}\text { Condition } \\
\text { Index }\end{array}$ \\
\hline incorrect procedures (IP) & .746 & .760 & 1.316 & 2.049 \\
extra procedures (EP) & .616 & .663 & 1.507 & 2.256 \\
omitted procedures (OP) & .329 & .846 & 1.181 & 3.087 \\
reference to glossary for CPM & .176 & .910 & 1.098 & 4.214 \\
parts (RG) & & & & \\
\hline
\end{tabular}

\section{Discussion}

\section{Limitations}

There were a number of limitations in the study, where applicable suggestions for future research have been made. First, this study did not include a second task, which required a higher level of decisionmaking content. For example, a trouble-shooting or repair task might have provided clearer data on whether deeper learning actually occurred. Second, although the pictorial materials presented in the instruction manuals were high quality laser copies, they were not the original photographs. As such, this may have reduced the resolution of the pictorial materials; thus reducing the clarity of information depicted in the pictures. Third, the samples for each condition were small, which limits the generalizability of the present findings. Thus, interpretation of the results should be taken with caution. Future research should attempt to utilize original photographs of the pictorial material in each instruction. The study also assumed that the arrows were interpreted as they were intended; however, this was not measured. Future research could assess whether participants interpreted the arrows as suggestions for actions or simply attuned participants to relevant information. Finally, a larger sample size should be used to enhance the generalizability of future findings.

The results suggest that there was a redundancy effect when a picture of the assembled object was coupled with the Text-Pictorial and the Text-Pictorial-Arrows manuals. Future research may investigate the amount of pictorial information that is needed in a Text-Picture instruction manual format to facilitate correct and optimal performance on a procedural task. For example, manuals with pictures of subassemblies may be a more appropriate as opposed to a step-by-step pictorial format to measure the scope of informational potential that arrows carry.

Another option to assess how the information was interpreted is to utilize a task, which requires a more complex problem, such as a repair task to investigate the type of unique information that arrows may have conveyed. This may answer the question of whether the unique type of information required for a trouble-shooting task is different to the information-types described by Booher (1975) and Bieger and Glock (1984-85) as fundamental for the successful completion of an assembly task; that is, contextual, focus and action-step information. Multimedia literature (Garnier 2001) suggests that arrows contain contextual, structural and movement information and thus would help individuals process information faster and more effectively. 


\section{Pictures and arrows as information for actions}

Empirical evidence from the present study shows that a text only instruction manual was the least effective for conveying instructions in a novel task compared to using a text with a picture of the object, text-pictures and text-pictures with arrows. These results corroborate previous studies (Bieger \& Glock, 1984-85; Booher, 1975; Braby, et al., 1982; Garnier et al., 2000); Heiser et al., 2004; Lowe \& Pramono, 2006; Stone \& Glock, 1981), which suggest that text format was the least effective method to convey information for novel procedural tasks, such as assembling and operating a novel object. They also confirm the multimedia principle, which purports that instructions that contain words and pictures facilitate better instructions evidenced by superior performance in conditions that had at least one picture in both assembly and operation tasks compared to words alone (Fletcher \& Tobias, 2005; Mayer 2005b). Faster performances in the presence of a picture of the object and pictorial materials support the idea that words and pictures are actively processed using two distinct and/or complementary modes (Clark \& Paivio, 1991; Paivio, 1986). Therefore, it can be inferred that some degree of cue summation process occurred which facilitates faster comprehension and subsequent actions (Gropper, 1963; Hagen, 1974; Ryan \& Schwartz, 1956; Severin, 1967). Furthermore, the fact that participants in the text condition referred to a picture of the assembled object significantly more than those in the Text-Pictorial and TextPictorial-Arrows condition support the notion that including pictures in instruction manuals may serve as information that is used to monitor and confirm actions by actors, thus aiding overall performance (Brody, 1984; Cutting, 1982).

Improved performance in the presence of a picture of the assembled object, especially in the text manual, also suggests that the picture served as structural information which provided participants with either context and/or accurate expectation (Bagget \& Ehrenfeucht, 1988; Smith \& Goodman, 1984); thus facilitating better performance of the tasks (Cooper \& Sweller, 1987; Sternberg, 2006; Sweller, 2005; see also Norman, 1988). Overall, it was clear that a picture of the assembled object was a significant and crucial source of information for guiding actions. It is, however, not surprising that the impact of this structural information was diminished in the presence of text and pictorial information and when arrows were added. In other words, when step-by-step pictures and arrows were provided, a picture of the assembled object became less crucial.

The fact that adding arrows to text-pictorial materials improved performances overall points to the notion that pictures carry relevant visual information concerning the object, including directions of actions, and movement (Agrawala et al., 2003; Hegarty, 1992; Horton, 1994; Krull \& Sharp, 2006; Szlichcinski, 1979; Tversky et al., 2000). The results also suggest that augmenting this information provides further clarification of the meaning of the pictures and instructions (Kurata \& Egenhofer, 2005), as well as highlights specific affordances of objects (Garnier, 2001; Heiser \& Tversky, 2002; Tversky et al., 2000). Notwithstanding the marginal effects, the performance data showed that participants who used the TextPictorial-Arrows with a picture of the object manual were the only ones who did not commit irreversible errors; that is, they all assembled the object successfully the first time (please refer to Table 1, UA). This is of significance, especially if no one is present to give feedback that the object has been incorrectly assembled and if the errors in assembly can cause significant repercussions.

Current proponents of DE and ICT are well aware that one of the major issues associated with DE is that learners have more decisions to make about learning since there is limited dialogue with the instructor due to high-transactional distance. The present study's findings are, therefore, relevant since it suggests that arrows can function as attention-directing cues that prevent errors, or in a wider context serve as attention-directing cues that point out relevant information. Furthermore, Rouet's (2009) work suggests that when it comes to children using ICT there is a need for more directions to attune them to relevant information, especially when they use document-based learning materials, which are still predominantly used as the communication medium of choice (Kanuka, 2011). The present study extends previous works (Abrami et al., 2011; Kalyuga, 2009; 2012; Mayer, 2008) that recommend the use of arrows as attentiondirecting cues that act as an aid to reduce extraneous loads in learning situations; namely, it provides empirical evidence that arrows can facilitate superior performance.

Overall, results from the present study suggest that the addition of a picture of the assembled object, stepby-step pictures and arrows facilitated superior performance during assembly and operation of the object compared to a text only situation; thus indicating mental efficiency in the presence of pictures and arrows (Paas, Tuovinen, Tabbers, \& van Gerven, 2003; Paas \& van Merriënboer, 1993). 


\section{Implication for practice}

There are a number of implications that can be derived from the present study. One of the more important findings from this study is the fact that text-pictorial-arrows information led to the elimination of uncorrected errors, omitted procedures and in general improved performance on all categories.

Reason's (2002) work claims that leaving out necessary steps in a task is the most common type of human error, which if uncorrected may lead to more disastrous outcomes. A number of task properties that are likely to increase occurrence of omission errors are things such as high information loading, similar steps, steps that are functionally isolated or do not follow logical sequences, including steps where items to be acted upon are hidden. Cheyne, Carriere, and Smilek's (2006) work suggests that tasks that are boring are also prone to errors of omission. While this may be self-evident, what is not common sense is how to prevent and/or reduce these errors. For example, Kelley's work (2007) suggests that training someone to do a task, which creates a mental model of the task, does not necessarily reduce errors of omission; rather, what reduces errors of omission is if the task is viewed as salient.

Reason's (2002) work further showed that two of the top five methods of managing omissions are first some type of visible note(s) carried, attached to wall, doors or pin board - the crucial criterion being visibility. The other method is object positioning which entails positioning an object to a place that is visible and/or that one cannot avoid encountering. The point being that visibility or attuning one to an action to be performed is an important method to combatting omission errors. The present study's finding suggest that arrows by the nature of their shape carry information that points out certain characteristics such as movement, location and/or relationship with other objects. These affordance properties of arrows are those that Reason (2002) actually claimed as visible information counteracting potential errors of omission.

\section{Recommendations for designing online tasks and instructions}

One of the major implications from the present study is for development and/or design of online learning resources. A task of analysis (Reason, 2002) of some online tasks such as online training is that it is long and boring. One of the issues associated with online learning is its independent nature, which may cause individuals to try to hurry up the task, especially in longer and/or boring tasks, which in turn may degrade performance (McElhatton \& Drew, 1993).

Further, related to the fact that DE and the use of ICT in instruction situations may involve limited dialogue with the instructor, online designers of instructional objects should consider the fact some of the materials may cause high cognitive loads on one's information processing system. This has been found to be most relevant for novice learners and children (Kalyuga, 2012; Rouet, 2009). For example, novice learners are sometimes overwhelmed by the amount of information to be searched. Therefore educators should design instructional objects that have clear and "appropriate scaffolding to provide sufficient instructional guidance" (Kalyuga, 2012; p. 202; see also Kalyuga, 2009).

The next step to be addressed is identification of parts of the task that are prone to errors, such as omissions or skipping information, then choosing a visible note to attune users to those parts. This paper suggests that the high-level of transactional distance that exists in DE and/or when ICT is used as the main mode of instructional delivery compared to the tradition face-to-face mode necessitates designers of instructional objects to engage learners in appropriate cognitive processing without overloading the cognitive capacity of the learner (Abrami et al., 2011).

This discussion leads to the following recommendations, in particular to ensure that instructional objects contain sufficient information for instructional guidance and reduce extraneous cognitive loading during learning:

1. Acknowledge that delivery of DE and instructional objects such as those using ICT such as digital audios and videos involves high-level of transactional distance (Abrami et al., 2011; Kanuka, 2011; Khoshemehr \& Nazemi, 2013).

2. Design instructional objects with a learner-centred approach in mind (Simonson et al., 2011) ensuring that there is ease and effective learner-content interaction (Bol \& Garner, 2011); following the principle of least effort (Abrami et al., 2011). 
3. Due to the high-level of transactional distance, conduct a task analysis of the instructional object; ensure that it has sufficient instructions for the learner (Abrami et al., 2011; Kalyuga, 2009; 2012).

4. Identify parts of the task and/or instructional object that require high information loading and/or parts that are boring within the instructional object (McElhatton \& Drew, 1993; Reason, 2002).

5. Reduce cognitive load by preventing cognitive overload (Kalyuga, 2012) in a manner that enables learners to attune to relevant information at the appropriate times.

a. Package the instructional objects into optimal sequences to enhance comprehension (Abrami et al., 2011; Alexander \& Hammond, 2012; Khoshemehr \& Nazemi, 2013),

b. Make salient parts that require high information loading and/or are boring by using colours and arrows to attune users to instructions or parts that are important at appropriate times.

c. Use the colours of red, green, yellow or orange to attune users (Chung \& Byrne, 2004).

d. Provide a picture of the goal, and pictures of key steps to attune users to important parts of the steps. For example, if it is online fire safety training, then provide pictures of equipment and use arrows to attune users to the parts that are important and/or provide pictures of locations and use arrows to pin point important areas.

\section{Conclusions}

The present study empirically demonstrated that text-only instruction manuals (i.e., no picture of goal or other visual representations) are least effective. It showed that combinations of pictorial information with text-only information facilitate significant improvements on both novel assembly and operating tasks. It demonstrated that a picture of the assembled object was crucial information for these tasks. These findings support the multimedia principle; namely, combining words and pictures facilitate better instructions. Therefore, whenever possible, appropriate pictures or illustrations as well as other visual representations should be presented with written text to assist instructions for complex tasks. If financial cost is a major constraint, then a text instruction manual should at least include a picture of the assembled object or pictures of sub-assembled objects. Simple augmentation using information such as arrows has been found to be very cost effective compared to augmenting instructional objects with audios or videos (Simonson et al. 2011).

This study also revealed a caveat; namely, too much information can cause interference to practical performance. The interaction effect when a picture of the assembled object was coupled with textpictorial and text-pictorial-arrows manuals, as well as patterns of redundancy although not significant suggests that systematic textual and step-by-step pictorial information may be excessive to process. Therefore, when instructions are able to provide a clear informative picture of the assembled object, adding sub-assembly pictures or illustrations may be sufficient.

Findings point to the notion that information has affordance properties. If we accept the view that affordances are properties of something that carry meaningful information for the individual; it is then valid to classify relevant pictures as having affordance properties since they carry meaningful information that reduces uncertainty and informs readers of potential actions especially when augmented. The study demonstrated that a text-pictorial-arrows format is the most effective for conveying complex procedural instructions. Further, it is important to note that it was the only format that did not have an unsuccessful assembly of the object. Arrows, therefore, should be presented in a text-picture format when conveying a complicated set of procedural instructions, especially when irreversible errors may cause detrimental or fatal effects.

The present study also lends support to the notion that attuning people to relevant information is important in instructional contexts. As such, it supports and advances Gibson's (1979) view that one of the fundamental tasks for educators is to attune learners to relevant variables pertinent to a knowledge area. Similarly, proponents of the multimedia principle (Mayer 2005a) also argued that learning involves knowledge construction. Thus, the role of an instructor or instruction is to provide guidance on how to process information and reduce the cognitive load during learning situations. Results of the present study empirically show that adapting and augmenting multimedia enhances instructions. Therefore, augmenting text and pictorial information in instructions can serve as aids in instructional contexts. 


\section{References}

Abrami, P. C., Bernard, R. M., Bures, E. M., Borokhovski, E., \& Tamim, R. M. (2011). Interaction in distance and online learning: using evidence and theory to improve practice. Journal of Computing in Higher Education, 23, 82-103.

Agrawala, M., Phan, D., Heiser, J., Haymaker, J., Klinger, J., Hanrahan, P., \& Tversky, B. (2003). Designing effective step-by-step assembly instructions. ACM Transaction on Graphics, 22(3), 828837.

Alexander, C., \& Hammond, T. C. (2012). Five-picture charades: A flexible model for technology training in digital media tools and teaching strategies. Contemporary Issues in Technology and Teacher Education, 12(1), 55-70.

Ayres, P., \& Paas, F. (2007). Making instructional instructions more effective: A cognitive load approach. Applied Cognitive Psychology, 21(6), 695-700.

Baggett, P., \& Ehrenfeucht, A. (1988). Conceptualizing in assembly task. Human Factors, 30, 269-284.

Bieger, G. R., \& Glock, M. D. (1984-85). The information content of picture-text instruction. The Journal of Experimental Education, 53, 68-76.

Bol, L., \& Garner, J. (2011). Challenges in supporting self-regulation in distance education environments. Journal of Computing in Higher Education, 23, 104-123.

Booher, H. R. (1975). Relative comprehensibility of pictorial information and printed words in proceduralized instructions. Human Factors, 17, 266-277.

Borghi, A. M. (2004). Objects concepts and action: Extracting affordances from object parts. Acta Psychologica, 115, 69-96.

Braby, R. J., Kincaid, P., \& McDaniel, W. C. (1982). Illustrated formats to teach procedures. IEEE Transactions on Professional Communication, 25, 61-66.

Brody, P. J. (1984). In search of instructional utility: A function-based approach to pictorial research. Instructional Science, 13, 47-61.

Bruce, V., \& Green, P. (1990). Visual perception physiology, psychology and ecology (2nd ed.). Hillsdale, NJ: Erlbaum.

Cheyne, J. A., Carriere, J. S. A., \& Smilek, D. (2006). Absent-mindedness: Lapses of conscious awareness and everyday cognitive failures. Consciousness and Cognition, 15, 578-592.

Chung, P. H., \& Byrne, M. D. (2004). Visual cues to reduce errors in a routine procedural task. Proceedings of the Twenty-Sixth Annual Conference of the Cognitive Science Society. Hillsdale, NJ: Lawrence Erlbaum Associates.

Clark, J. M., \& Paivio, A. (1991). Dual coding theory and education. Educational Psychological Review, $3(3), 149-210$.

Cooper, D. R., \& Schindler, P. S. (2003). Business research methods. New York: McGraw-Hill.

Cooper, G., \& Sweller, J. (1987). The effects of schema acquisition and rule automation on mathematical problem-solving transfer. Journal of Educational Psychology, 79, 347-362.

Crandell, T. L. (1979). The effects of cognitive style elements on the comprehension of reading procedure information in picture text amalgams (Unpublished doctoral dissertation). Cornell University, USA.

Cutting, J. E. (1982). Two ecological perspectives: Gibson vs. Shaw and Turvey. American Journal of Psychology, 95, 199-222. 
Cutting, J. E. (1986). Perception with an eye for motion. Cambridge, MA: MIT Press.

Cutting, J. E. (1987). Perception and information. Annual Review of Psychology, 38, 61-90.

de Koning, B. B., Tabbers, H. K., Rikers, R. M. J. P., \& Paas, F. (2007). Attention cueing as a means to enhance learning from an animation. Applied Cognitive Psychology, 21(6), 731-746.

Dixon, P. (1982). Plans and written directions for complex tasks. Journal of Verbal Learning and Verbal Behavior, 21, 70-84.

Everitt, B. S. (1996). Making sense of statistics in psychology. Oxford: Oxford University Press.

Fletcher J. D., \& Tobias, S. (2005). The multimedia principle. In R. E. Mayer (Ed.), The Cambridge handbook of multimedia learning (pp. 117-133). New York, NY: Cambridge University Press.

Franks, A., \& Jewitt, C. (2001). The meaning of action in learning and teaching. British Educational Research Journal, 27(2), 201-218.

Friedman, S. L., \& Stevenson, M. B. (1980). Perception of movement in pictures. In M. A. Hagen (Ed.), The perception of pictures Volume I. Alberti's window: The projective model of pictorial information (pp. 225-256). New York, NY: Academic Press.

Garnier, F. (2001). Processing text and pictures in procedural instructions. Information Design Journal, $10(2), 146-153$.

Gibson, J. J. (1966). The theory of information pickup: The senses considered as perceptual systems. Boston, MA: Houghton-Mifflin.

Gibson, J. J. (1971). The information available in pictures. Leonardo, 4, 27-35.

Gibson, J. J. (1979). The ecological approach to visual perception. Boston, MA: Houghton-Mifflin.

Gropper, G. L. (1963). Why is a picture worth a thousand words? Audio Visual Communication Review, $11,75-95$.

Hagen, M. A. (1974). Picture perception: Toward a theoretical model. Psychological Bulletin, 81, 471497.

Hagen, M. A. (1980). Generative theory: A perceptual theory of pictorial representation. In M. A. Hagen (Ed.), The perception of pictures, Volume II. Durer's devices: Beyond the projective model of pictures (pp. 3-46). New York, NY: Academic Press.

Halliday, M. (1978). Language as a social semiotic. London: Arnold.

Hegarty, M. (1992). Mental animation: Inferring motion from static displays of mechanical systems. Journal of Experimental Psychology: Learning, Memory and Cognition, 18(5), 1084-1102.

Heiser, J., Phan, D., Agrawala, M., Tversky, B., \& Hanrahan, P. (2004). Identification and validation of cognitive design principles for automated generation of assembly instructions. Proceedings of the working conference on advanced visual interfaces, Italy, 311-319.

Heiser, J., \& Tversky, B. (2002). Diagrams and descriptions in acquiring complex systems. Proceedings of the 24th Cognitive Science Society. Fairfax, VA, 447-452.

Hodge, R., \& Kress, G. (1988). Social semiotics. London, Polity Press.

Hodgkinson, R., \& Hughes, J. (1982). Developing wordless instructions: A case history. IEEE Transaction on Professional Communication, 25, 74-79. 
Horton, W. (1994). The icon book. Brisbane: John Wiley \& Sons.

Houts, P. S., Doak, C. C., Doak, L. G., \& Loscalzo, M. J. (2006). The role of pictures in improving health communication: A review of research on attention, comprehension, recall and adherence. Patient Education and Counseling, 61, 173-190.

Jewitt, C. (2005). Classrooms and the design of pedagogic discourse: A multimodal approach. Culture Psychology, 11, 309-320.

Jewitt, C., Kress, G., Ogborn, J., \& Tsatsarelis, C. (2001). Exploring learning through visual, actional and linguistic communication: The multimodal environment of a science classroom. Educational Review, $53(1), 5-18$

Kalyuga, S. (2009). Knowledge elaboration: a cognitive load perspective. Learning and Instruction, $19(5), 402-410$.

Kalyuga, S. (2012). Interactive distance education: a cognitive load perspective. Journal of Computing in Higher Education, 24, 182-208.

Kanuka, H. (2011). Interaction and the online distance classroom: Do instructional methods effect the quality of interaction? Journal of Computing in Higher Education, 23, 143-156.

Kelley, K. D. (2007). An exploration of internal cues to reduce omission errors in a procedural task (Unpublished master's thesis), Faculty of Life Sciences, University College London. Retrieved from http://www.ucl.ac.uk/uclic/taught_courses/distinction/2006_theses/kelley.pdf

Khoshemehr, A. H., \& Nazemi, Y. (2013). Distance education: Role and position of information management. International Journal of Basic Sciences \& Applied Research. 2(2), 215-222.

Kleinbaum, D., Kupper, L., \& Muller, K. (1988). Applied regression analysis and other multivariable methods. Boston, MA: PWS-Kent.

Krull, R., D'Souza, J. S., Roy, D., \& Sharp, M. D. (2004). Designing procedural illustrations. IEEE Transactions on Professional Communication, 47(3), 27-33.

Krull, R., \& Sharp, M. (2006). Visual verbs: Using arrows to depict the direction of actions in procedural illustrations. Information Design Journals, 14(3), 189-198.

Kugler, P. N., \& Turvey, M. T. (1987). Perspective on rhythmic movement. In P. N. Kugler \& M. T. Turvey (Eds.), Information, natural law, and the self-assembly of rhythmic movement (pp. 1-10). Hillsdale, NJ: Erlbaum.

Kurata, Y., \& Egenhofer, J. M. (2005, March). Semantics of simple arrow diagrams. Association for the Advancement of Artificial Intelligence Spring Symposium Series. Stanford University, CA. Retrieved from http://www.aaai.org/Papers/Symposia/Spring/2005/SS-05-06/SS05-06-020.pdf

Lawal, I, R., \& Oloyede, M. O. (2013). Enhancing the quality of learning and teaching via information communication and technology (ICT). International Journal of Applied Information Systems, 5(4), $42-50$.

Lowe, R., \& Pramono, H. (2006). Using graphics to support comprehension of dynamics in texts. Information Design Journal, 14(1), 22-34.

Malapile, S., \& Keengwe, J. (2013). Information communication technology planning in developing countries. Education and Information Technologies, online 19 January 2013. Retrieved from http://link.springer.com/content/pdf/10.1007\%2Fs10639-013-9248-x

Mayer, R. E. (2005a). Introduction of multimedia learning. In R. E. Mayer (Ed.), The Cambridge handbook of multimedia learning (pp. 1-16). New York, NY: Cambridge University Press. 
Mayer, R. E. (2005b). Cognitive theory of multimedia learning. In R. E. Mayer (Ed.), The Cambridge handbook of multimedia learning (pp. 31-48). New York, NY: Cambridge University Press.

Mayer, R. E. (2008). Learning and instruction (2nd ed.). Upper Saddle River, NJ: Merrill Prentice-Hall.

Mayer, R. E., \& Gallini, J. K. (1990). When is an illustration worth ten thousand words? Journal of Educational Psychology, 82(4), 715-726.

Mayer, R. E., Hegarty, M., Mayer, S., \& Campbell, J. (2005). When static media promote active learning: Annotated illustrations versus narrated animations in multimedia instructions. Journal of Experimental Psychology: Applied, 11, 256-265.

Mayer, R. E., \& Sims, V. K. (1994). For whom is a picture worth a thousand words? Extensions of a dual-coding theory of multimedia learning. Journal of Educational Psychology, 86(3), 389-401.

McElhatton, J., \& Drew, C. (1993). Hurry-up syndrome. Aviation Safety Reporting System Direct Line, 5(March). Retrieved from http://asrs.arc.nasa.gov/publications/directline/d15_hurry.htm

Moore, M. (1989). Three types of interaction. American Journal of Distance Education, 3(2), 1-6.

Nailen, R. L. (1981). An engineer's guide to clear language. IEEE Transaction on Professional Communication, 24, 117-119.

Najjar, L. J. (1998). Principles of educational multimedia user interface design. Human Factors, 40(2), 611-623

Norman, D. A. (1988). The psychology of everyday things. New York, NY: Basic Books.

Paas, F., Tuovinen, J. E., Tabbers, H., \& van Gerven, P. W. M. (2003). Cognitive load measurement as a means to advance cognitive load theory. Educational Psychologist, 38(1), 63-71.

Paas, F., \& van Merriënboer, J. J. G. (1993). The efficiency of instructional conditions: An approach to combine mental effort and performance measures. Human Factors, 35, 737-743.

Paivio, A. (1986). Mental representations: A dual coding approach. New York, NY: Oxford University Press.

Rabbitt, P. (1984). The control of attention in visual search. In R. Parasuraman \& D. R. Davies (Eds.), Varieties of attention (pp. 273-291). New York, NY: Academic Press.

Rasmussen, J. (1983). Skills, rules, and knowledge: Signals, signs, and symbols, and other distinction in human performance models. IEEE Transactions on Systems, Man, and Cybernetics, 3, 257-268.

Reason, J. T. (2002). Combating omission errors through task analysis and good reminders. Quality Safety Health Care, 11, 40-44,

Resnick, L. B. (1976). Task analysis in instructional design: Some cases from mathematics. In D. Klahr (Ed.), Cognition and instruction (pp. 51-80). New York, NY: Erlbaum.

Rouet, J-F. (2009). Managing cognitive load during document-based learning. Learning and Instruction, $19,445-450$.

Ryan, T. A., \& Schwartz, C. (1956). Speed of perception as a function of mode representation. American Journal of Psychology, 69, 60-69.

Sadoski, M., Paivio, A., \& Goetz, E. T. (2003). A critique of schema theory in reading and a dual coding alternative. Reading Research Quarterly, 26(4), 463-484.

Schmidt-Weigand, F., \& Scheiter, K. (2011). The role of spatial descriptions in learning from multimedia. Computers in Human Behavior, 27, 22-28. 
Seufert, T., Schütze, M., \& Brünken, R. (2009). Memory characteristics and modality in multimedia learning: An aptitude-treatment-interaction study. Learning and Instruction, 19(1), 28-42.

Severin, W. J. (1967). Another look at cue summation. AV Communication Review, 15, 233-245.

Simonson, M., Schlosser, C., \& Orellana, A. (2011). Distance education research: A review of the literature. Journal of Computing in Higher Education, 23, 124-142.

Smith, E. E., \& Goodman, L. (1984). Understanding written instructions: The role of an explanatory schema. Cognition and Instruction, 1, 359-396.

Sternberg, G. (2006). Conceptual factors in the picture superiority effect. European Journal of Cognitive Psychology, 18(6), 813-847.

Stone, D. E., \& Glock, M. D. (1981). How do adults read directions with and without pictures? Journal of Educational Psychology, 73, 419-426.

Sweller, J. (1988). Cognitive load during problem solving: Effects on learning. Cognitive Science, 12, 257-285.

Sweller, J. (2005). Implications of cognitive load theory for multimedia learning. In R. E. Mayer (Ed.), The Cambridge handbook of multimedia learning (pp. 19-30). New York, NY: Cambridge University Press.

Sweller, J., van Merriënboer, J. J. G., \& Paas, F. G. W. (1998). Cognitive architecture and instructional design. Educational Psychology Review, 10(3), 251-296.

Szlichcinski, K. P. (1979). Diagrams and illustrations as aids to problem solving. Instructional Science, 8 , 253-274.

Tabbers, H. K., Martens, R. L., \& van Merriënboer, J. J. G. (2004). Multimedia instructions and cognitive load theory: Effects of modality and cueing. British Journal of Educational Psychology, 74, 71-81.

Thom, R. (1975). Structural stability and morphogenesis. Reading, MA: Benjamin.

Turvey, M. T. (1977). Preliminaries to a theory of action with reference to vision. In R. Shaw \& J. Bransford (Eds.), Perceiving, acting and knowing (pp. 211-265). Hillsdale, NJ: Erlbaum.

Tversky, B., Zacks, J., Lee, P., \& Heiser, J. (2000). Lines, blobs, crosses and arrows: Diagrammatic communications with schematic figures. In M. Anderson, P. Cheng, \& V. Haarslev (Eds.), Diagrams (pp. 221-230). Heidelberg, Berlin: Springer-Verlag.

van Leuween, T. (2006). Towards a semiotics of typography. Information Design Journal and Document Design, 14(2), 139-155.

Watt, R. (1991). Understanding vision. London: Academic Press.

Corresponding author: Andre A. Pekerti, a.pekerti@business.uq.edu.au

Australasian Journal of Educational Technology (C) 2013.

Please cite as: Pekerti, A. A. (2013). Augmentation of information in educational objects: Effectiveness of arrows and pictures as information for actions in instructional objects. Australasian Journal of Educational Technology, 29(6), 840-869. 


\section{Appendix 1}

Sample instructions for the CPM unit, the first 6 pages of the instructions manual. (lines represent page breaks, and italicized notes were not present in the actual instruction manuals).

THE CPM UNIT:

ASSEMBLY AND TESTING INSTRUCTIONS

Table of Contents

The CPM Unit

Contents

Names of CPM Parts

1

Assembly and Testing Procedure Instructions

Cursor Shaft Assembly

Hand Rod Assembly

5

Cursor Casing Assembly

$6-10$

Finger Linkage Assembly

$11-12$

13

14-17

Testing Procedures

$18-20$

Test With Plug in Cursor Casing Position

$21-23$

\section{The CPM unit}

\section{The CPM Unit}

The portable continuous passive motion hand unit (CPM) is an orthopaedic hand exercise unit, designed to help the healing of the hand and/or finger muscles after injury. The lightweight design of the unit means the patient can take the unit home and supervise their own personal therapy for up to 24 hours.

The unit fits comfortably on top of the hand and wrist. It is secured with Velcro binding for easy attachment to and release from the fingers and wrist.

A small motor operates the finger linkages of the CPM unit, which helps the patient to exercise his/her, hand without effort.

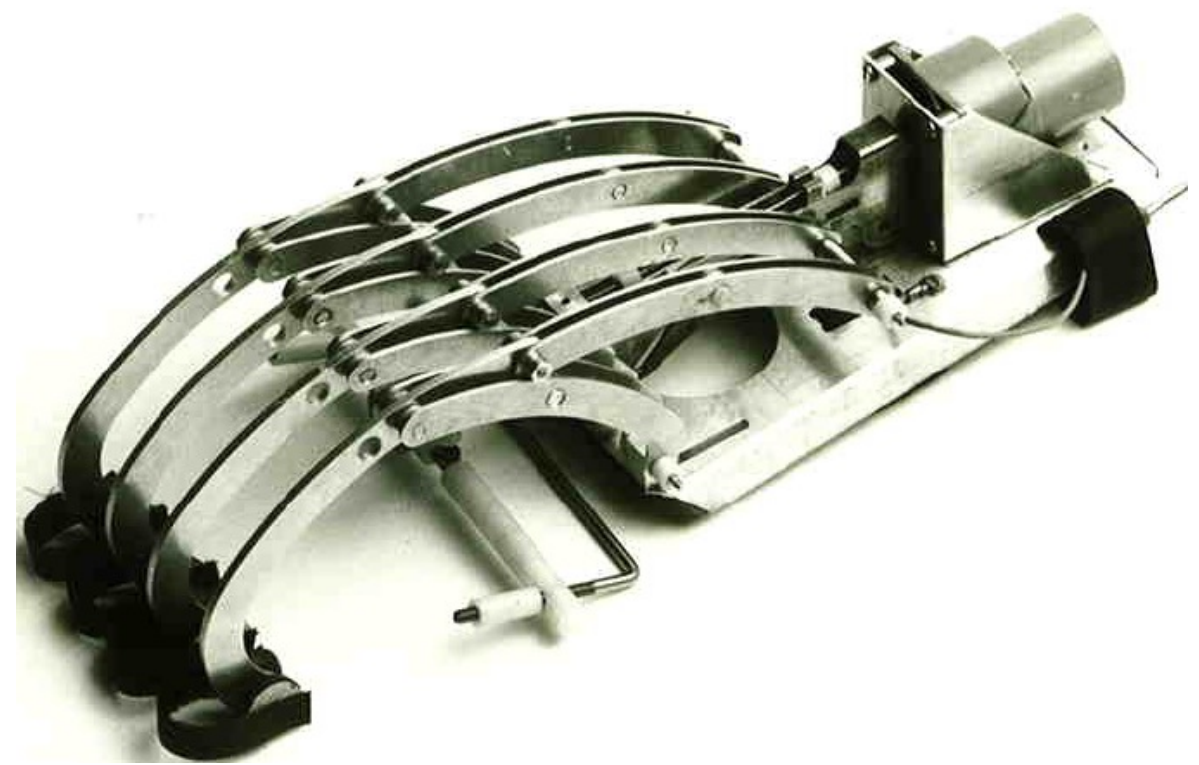

Picture 1. The CPM Unit.

Note: This CPM picture was present in Conditions 2, 4, and 6, but not in Conditions 1, 3, and 5. 


\section{Names of CPM parts}

1.0) Names of CPM Parts



Picture 2. Names of CPM Parts.

The following names refer to the names of the CPM parts and their location on the CPM unit. The order of presentation corresponds with the order of the procedural steps.

Note: the labelled picture was absent in Conditions 1 and 2.

A) The CPM Base Unit: The CPM base unit is the largest sub-assembled component made up of an aluminium base-plate, a motor unit, a red plug, and 4 linkage attachment blocks.

B) The Cursor Shaft: The cursor shaft is the longest metal rod with a brass block threaded onto it. The cursor shaft is attached to the motor shaft.

C) The Switch Rod: The switch rod is the brass rod with 2 short plastic nuts threaded onto it. The switch rod is attached to the motor unit.

D) The Cursor: The cursor is the brass block with 2 holes and a groove. The cursor is threaded onto the cursor shaft.

E) The Allen Screw: The Allen screw is the screw threaded into the white portion of the cursor shaft.

F) The Motor Shaft: The motor shaft is the small metal rod protruding from the motor unit.

G) The Cursor-Shaft-Block: The cursor-shaft-block is the long rectangular block with holes on it. The cursor-shaft-block is fastened onto the CPM unit base-plate.

H) The Bolt Rod: The bolt rod is the long brass rod with a short plastic nut threaded onto it. The bolt rod secures the finger linkages onto the CPM unit.

I) The screw: The screw is the smallest un-assembled CPM component. The screw secures the cursorshaft-block onto the CPM unit base-plate.

J) The T-Bar: The T-bar is the metal component, which represents the alphabetical letter 'T', a short plastic nut is threaded onto it. The T-bar is a subpart of the hand rod unit fastened onto the cursor casing. 
K) The Plastic Sleeves: The plastic sleeves are the longest plastic component of the CPM parts. Each plastic sleeve is partially hollow with a hole on one end. The plastic sleeves are a sub-part of the hand rod unit slotted onto the T-bar.

L) The U-Bar: The U-bar is the metal component, which represents a very wide alphabetical letter 'U'. The U-bar is a sub-part of the hand rod unit and is fastened to the T-bar.

M) The Long Plastic Nut: The long plastic nut is the longest nut of the CPM parts. It is a sub-part of the hand rod unit, which secures the U-bar to the T-bar.

N) The Cursor Casing: The cursor casing is the largest metal component of the CPM parts. The cursor casing is an aluminium block with 6 holes fixed between the metal at the front-end, with gaps in the midsection and one hole at the back-end of the metal part. The cursor casing encases the cursor and the cursor-shaft-block.

0) The Finger Linkages: The finger linkages are the 3-pronged aluminium objects with a black Velcro strip fastened at the front-end. The finger linkages are attached to the CPM base unit in 2 places: 1) the 4 linkage attachment blocks. 2) the cursor.

P) The Attachment Blocks: The attachment blocks are the 4 short metal blocks secured onto the frontend of the CPM unit base-plate.

Q) The Plastic Nut: The plastic nut is the shortest plastic component of the CPM parts. The nut secures the bolt rods attaching the finger linkages to the attachment blocks and the cursor.

R) The Aluminium Spacer: The aluminium spacer is the hollow, pipe-like aluminium component of the CPM parts. The aluminium spacer is slotted onto the bolt rod between the back finger linkage attachments.

S) The Motor Unit: The motor unit is the sub-assembled component secured to the back-end of the CPM unit base-plate.

T) The Plug: The (red) plug is attached to the black Velcro strap located at the back-end of the CPM base unit.

U) The Adapter: The adapter is the black 'cubical' object with a silver socket attached to the black cord.

V) The Direction Switch: The direction switch is the brown PC board located on the top of the motor unit.

W) The Adapter Plug: The adapter plug is the silver metal rod that protrudes from the back end of the motor unit.

\section{Assembly and Testing Procedure Instructions}

All the parts and tools you will need to assemble and operate the CPM unit are in front of you.

1) Perform the task as accurately and as fast as you can.

2) Please follow the procedures and notes in a step-by-step manner.

Please close the manual.

Note: The assembly process and timing does not start until participants are told to re-open the manual and begin assembling. 


\section{Assembly Procedures}

\section{0) Cursor Shaft Assembly}

The cursor shaft is the metal shaft, which is threaded through the cursor. When the motor is operating, the cursor allows for forward and backward motion of the finger linkages.

\section{1) Positioning the cursor shaft into the motor shaft:}

1) Position the CPM base unit so that the 4 linkage attachment blocks are facing you.

2) Select the cursor shaft.

3) With one hand, lift the switch rod.

4) With your other hand. Position the cursor shaft below the switch rod.

5) Place the switch rod in the groove of the cursor. (Note: The cursor should be positioned between the 2 plastic nuts.)

6) Turn the cursor shaft so that the Allen screw is aligned with the flat side of the motor shaft.

7) Insert the cursor shaft into the motor shaft as far as you can.

Proceed to the next page.

Note that all the other conditions received the same set of text instructions.

\section{Appendix 2}

Sample instructions for the CPM unit in Text Format, steps 9 through 12, for Mounting the cursorshaft-block onto the CPM base unit.

Note: Picture 1 - The CPM picture was present in Condition 2 (text with a picture of the assembled object) but not in Condition 1 (text-only instructions). And all the text was identical in all 6 conditions.

\section{2) Mounting the cursor-shaft-block onto the CPM base unit:}

9) Hold the CPM unit firmly and ensure that the cursor-shaft-block is touching the table.

10) With the screw, secure the cursor-shaft-block to the CPM unit base-plate.

11) Using the screwdriver, tighten the screw.

12) Turn the unit back over and position the CPM base unit so that the 4 attachment blocks are facing you.

Proceed to the next page. 


\section{Appendix 3}

Sample instructions for the CPM unit in Text-Pictorial Format, steps 9 through 12, for Mounting the cursor-shaft-block onto the CPM base unit.

Note: Picture 1 - The CPM picture was present in Condition 4 (text-pictorial with a picture of the assembled object) but not in Condition 3 (text-pictorial instructions).

\section{2) Mounting the cursor-shaft-block onto the CPM base unit:}

9) Hold the CPM unit firmly and ensure that the cursor-shaftblock is touching the table.

10) With the screw, secure the cursor-shaft-block to the CPM unit base-plate.

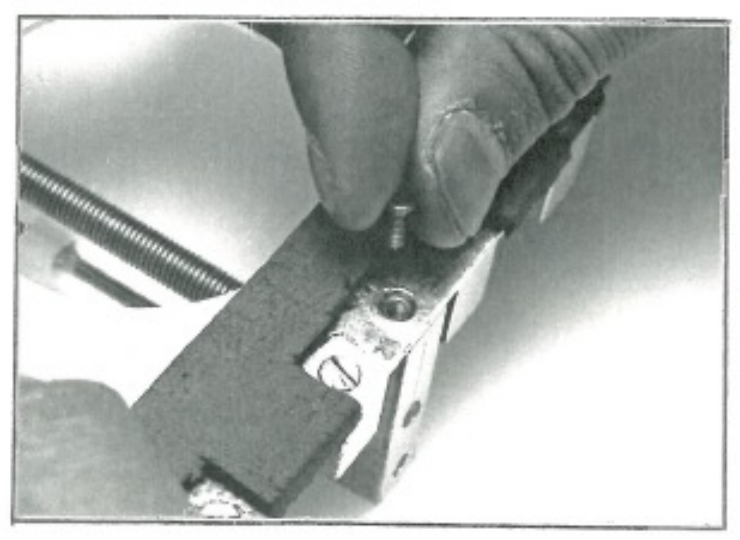

11) Using the screwdriver, tighten the screw.

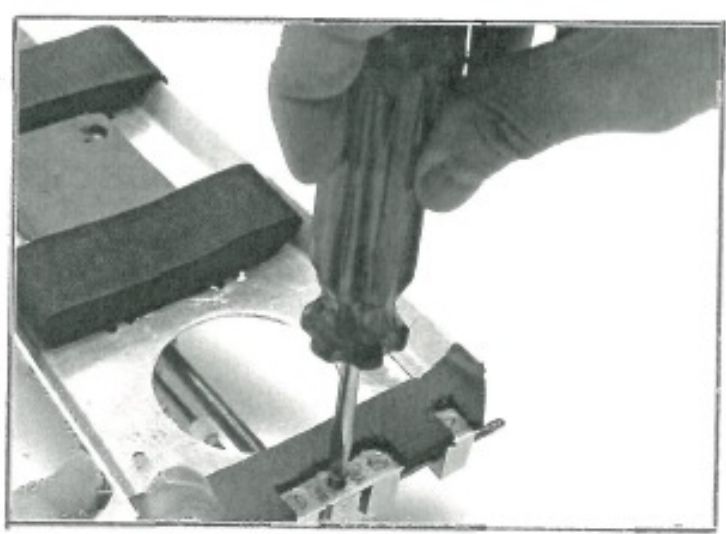

12) Turn the unit back over and position the CPM base unit so that the 4 attachment blocks are facing you.

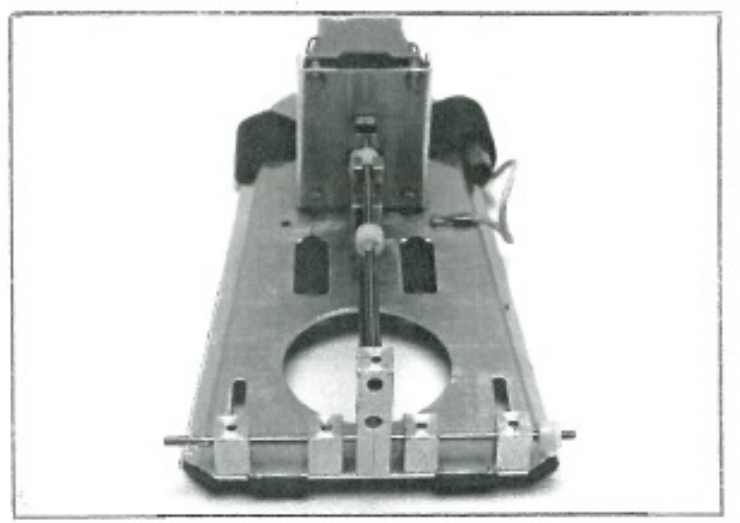

Proceed to the next page. 


\section{Appendix 4}

Sample instructions for the CPM unit in Text-Pictorial-Arrows Format, steps 9 through 12, for Mounting the cursor-shaft-block onto the CPM base unit.

Note: Picture 1 - The CPM picture was present in Condition 6 (text-pictorial-arrows with a picture of the assembled object) but not in Condition 5 (text-pictorial-arrows instructions).

\section{2) Mounting the cursor-shaft-block onto the CPM base unit:}

9) Hold the CPM unit firmly and ensure that the cursor-shaftblock is touching the table.

10) With the screw, secure the cursor-shaft-block to the CPM unit base-plate.

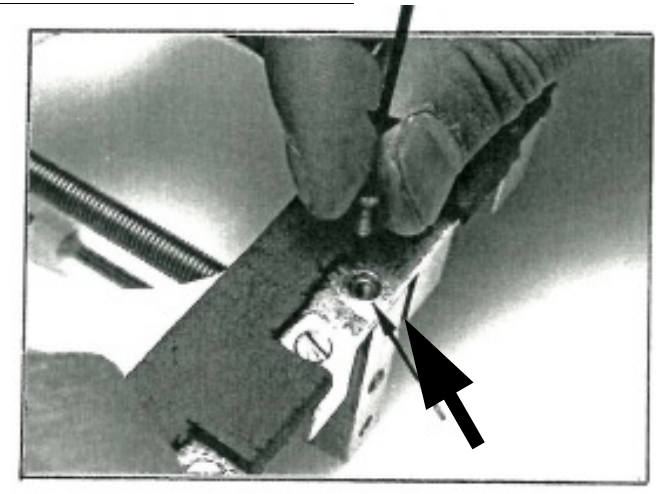

11) Using the screwdriver, tighten the screw.



12) Turn the unit back over and position the CPM base unit so that the 4 attachment blocks are facing you.

Proceed to the next page.

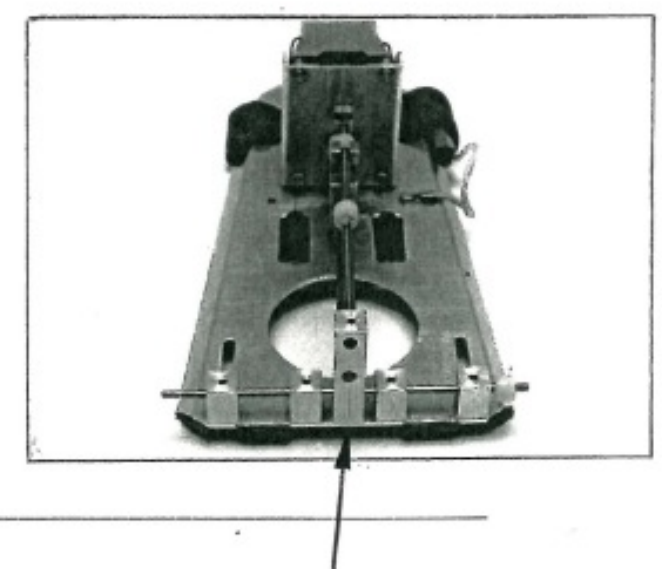

Note: Top frame - is an example of pictorial, arrow information depicting direction of movement and pointing. Middle frame - example of arrow information depicting direction of movement. Bottom frameexample of arrow information depicting location. Conditions 3 and 4 had the same pictures but no arrows; Conditions 5 and 6 had identical arrows information. 


\section{Appendix 5}

\section{Performance classifications for coding tasks}

1) Incorrect procedure(s), (error); designates a subjects' performance of not fulfilling or incorrectly performing what the instructions state.

2) Extra procedure(s); classifies a subject's action of performing an extra procedure after fulfilling the required action or performing an additional action that is not stated in the instructions (regardless of whether it is positive or negative).

3) Omitted procedure(s) (error); designates a subject's action of failing to perform a procedure/step stated in the instruction manual.

4) Reference to glossary for CPM parts; classifies a subjects' action of looking back at the picture of names of CPM parts and names of CPM parts.

5) Unsuccessful assembly or Unsuccessful testing [in the testing procedure section of the task] (error); designates a situation where a subject have incorrectly assembled the CPM unit after subject notifies experimenter that they have finished assembling.

Note: The category named 'Extra procedure(s)' and 'Reference to glossary for CPM parts' is not an error category, those categories are monitored for explanatory purposes.

\section{Appendix 6}

\section{Assembly Task Performance}

Incorrect procedure - IP: Not fulfilling and/or incorrectly performing what the instructions stated. A behavior was classified as an error by virtue of its failure to conform with a chosen standard of correctness (Reason, 1990) or adherence to the instruction manual.

Extra procedure - EP: Performing an extra procedure after having fulfilled the required action or, performing an additional action that was not stated in the instructions (regardless of whether it had positive or negative effect).

Omitted procedure - $\boldsymbol{O P}$ : Failing to perform a procedure stated in the instructions.

Reference to glossary for CPM parts - $R \boldsymbol{G}$ : Looking back at descriptions of the CPM parts.

Unsuccessful assembly - UA: Incorrect assembly the CPM after the participant indicated that he/she had completed the task. Participants were given a second chance to correct the error(s) after given written feedback.

Assembly time - $\boldsymbol{A T}$ : Time assembling the CPM, including correcting errors.

Incorrect procedure during operation of CPM - IPO.

Extra procedure during operation of CPM - EPO.

Omitted procedure during operation of CPM-OPO.

Reference to glossary for CPM parts during operation of CPM-RGO.

Time operating CPM - TO.

Total performance time - TPT: Time taken to complete both assembly and operating CPM.

Utility ratings of glossary for CPM parts - UG: Ratings concerning the value of glossary of CPM parts during the whole task.

Reference to CPM picture during assembly: Looking back at descriptions of the CPM picture during assembly task. This variable was only tested in a post-hoc analysis. 